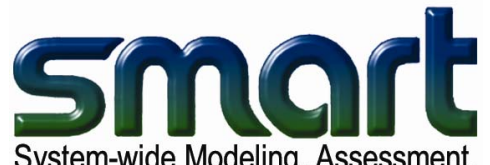

System-wide Modeling, Assessment and Restoration Technologies

\title{
Conceptual Models to Support Environmental Planning and Operations
}

by Jim E. Henderson and L. Jean O'Neil

PURPOSE: The purpose of this technical note is to provide guidelines on the use of conceptual models to improve system-wide planning and operation of water resource projects of the Corps of Engineers. Conceptual models provide a tool to represent, communicate, and analyze the structure, functions, and hierarchical relationships of the systems affected by Corps activities. The movement toward ecosystem restoration projects and toward sustainability of economic and ecologically viable systems has brought into

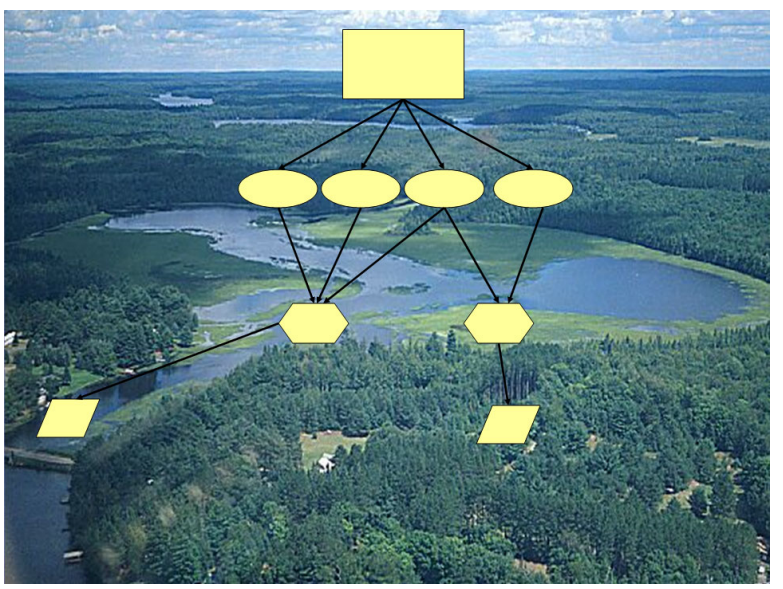
focus the need to approach some Corps activities on a system-wide basis including:

- Understanding the response of natural resources to environmental change or stress.

- Supplying reliable services, e.g., flood damage reduction, maintenance of biodiversity.

- Designing and managing projects in a sustainable manner.

Numerous models for physical, chemical, and biological processes have been developed and effectively applied to address site or local environmental decisions. Planning and management at the systemwide level require more comprehensive consideration of system components and interactions so that appropriate site or local and large-scale models are used. Conceptual

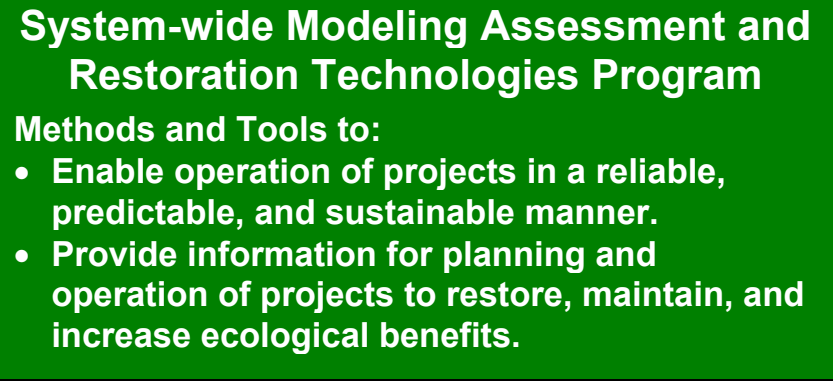
models can provide the basis for developing system-wide projects using the methods and tools developed in the System-wide Modeling, Assessment, and Restoration Technologies (SMART) Program.

For system-wide management to achieve the objectives of sustainability and ecosystem restoration, conceptual models provide the necessary mechanism and framework to comprehensively represent multiple system components, to communicate the interactions and connections of complex systems, and to identify significant resources, critical paths, and indicators of system functions. 
Applications of conceptual models in environmental planning include:

- Comprehensive system representation/cause and effect model. Organize information into a comprehensive representation of the system's important structure (components) and function (processes) and cause-and-effect relationships. The model components and relationships are used to assess and evaluate changes to the system; that is, use of the model as a simulation tool - effects of management actions, alternatives, and scenarios on the system and system structure and function. Hypotheses about uncertain relationships or interactions between components may be tested and revisions made to the model through an adaptive process. System organization may be at the site, watershed, basin, landscape, or ecosystem level.

- Communication. Provide a framework for communication and decision-making that incorporates different disciplines and a range of affected stakeholder and agency groups. Conceptual models are often used to communicate the important attributes, relationships, and interactions of complicated issues and complex systems. Stakeholder groups, agency functions (e.g., planning and operations), and technical disciplines typically relate to systems resource use and management independently. Thus conceptual models provide a means for integrating input from multiple sources and informing groups of the interactions, involvement, and dependencies of other groups.

- Critical path, monitoring, and indicators. Establish a framework to identify and inventory critical paths, important or dominating factors or elements, significant resources or changes, and indicators and report on them in a consistent framework (U.S. Environmental Protection Agency (USEPA) Science Advisory Board 2002). The identified components and their cause-and-effect relationships may be used to forecast and evaluate system effects on system integrity, stress, risks, and other changes.

SCOPE: The need to organize, evaluate, and communicate an array of system components is applicable to a number of System-wide Modeling, Assessment, and Restoration Technologies efforts. This technical note describes the use of conceptual models for system-wide applications that apply to Corps actions, and presents a general approach to conceptual model development for Corps applications. This approach is presented in six steps:

Step 1: Identify the objectives and uses of the model.

Step 2: Delineate the spatial and temporal scales or boundaries of the model.

Step 3: Identify the structural components of the system.

Step 4: Identify the sources of change in the system.

Step 5: Review the model.

Step 6: Implement the model.

This six-step approach is based on experience and on applications of conceptual modeling in a range of ecological settings, and illustrated with examples from the literature in text and figures and Table A1 in Appendix A. Many of the models described in this technical note have been developed for purposes that differ somewhat from water resources management, and nomenclature may vary from terms in the technical note. Appendix B is a glossary of terms the 
authors suggest. Regardless of differences in terms, however, the principles of conceptual model development remain the same. Readers are encouraged to provide feedback to the authors so improvements in the concepts and approach to conceptual modeling outlined in this technical note can be strengthened.

\section{CONCEPTUAL MODELS}

What is a Conceptual Model? A conceptual model is a representation of relationships among natural forces and factors, and human activities (intended or not) that are believed to impact, influence, or lead to an ecological or target condition. The target condition-e.g., lake water quality, habitat, level of risk - is significant or valued, ecologically and publicly (Margoluis and Salafsky 1998). The ecological or target condition may be on the scale of a single pond or as large as the Chesapeake Bay or South Florida. Conceptual models have been described as qualitative or descriptive narratives or graphic representations that demonstrate the causal relationships between natural forces and human activities that produce changes in human and ecological systems (Jorgensen 1988, Jorgensen et al. 1996, Odum 1983). Many conceptual models are characterized as influence diagrams, representing our understanding of causal relationships. Other models are representations of perceived relationships between system components or between existing, separate models. Graphical representations are the most common expression of a conceptual model, although word models are frequently used, sometimes as the precursor to a graphical representation.

Background of Conceptual Models. Current applications of conceptual models have their genesis in risk assessment frameworks (USEPA 1992, 1998), environmental impact assessment approaches (Canter 1986), and systems analysis and diagrams (Tighe and O'Neil, in preparation; Odum 1983; Grant 1986)).

EPA risk assessment. USEPA’s risk assessment framework (USEPA 1992, 1998) for contaminants provides a mechanism for explaining contaminant cause-and-effect relationships and for quantifying risk of contaminant exposure. In Figure 1, contaminant sources propagate contaminant movement through interactions with the two resource components-surface soil and water (wastewater, groundwater, and runoff). The contaminants interact through physical, chemical, and biological reactions and processes. These interactions result in exposure to contaminants by the biotic (e.g., vegetative litter) and abiotic (e.g., soil transport) sectorsaquatic biota, plants, herbivores, omnivores, invertebrates, and geomorphic components. The effects on the biotic groups are integrated to determine the risks to the aquatic, terrestrial, and groundwater system sub-models, with transfer of materials between the sub-models.

The model identifies changes in the system and thereby identifies the risk to humans, animals, and plants as a result of contaminant-caused changes in the water and soils. The resulting effects on health are accounted for by looking at the end results of these changes, and significance of the results, in the aquatic, terrestrial, and groundwater sub-systems. Determining changes requires measurement of some endpoint, indicative of the health effects, usually a species that is used to represent a group of plants, animals, or soil or other abiotic component. 
The intent of EPA's risk framework is to identify significant ecological risks and quantify them, based on the potential of contaminant release. The framework does not specifically address the natural or anthropogenic producers or production process of the contaminants, that is, the drivers of the system. EPA's risk framework - widely disseminated through academic, regulatory, and resource management interests - produced a dialogue on movement of human-induced changes through the environment, interactions between major subsystems of the environment, and evaluation of significance of the changes, i.e., risk to animals, plants, and humans. The framework provided an appropriate rationale for thinking about system-wide effects caused by human actions.

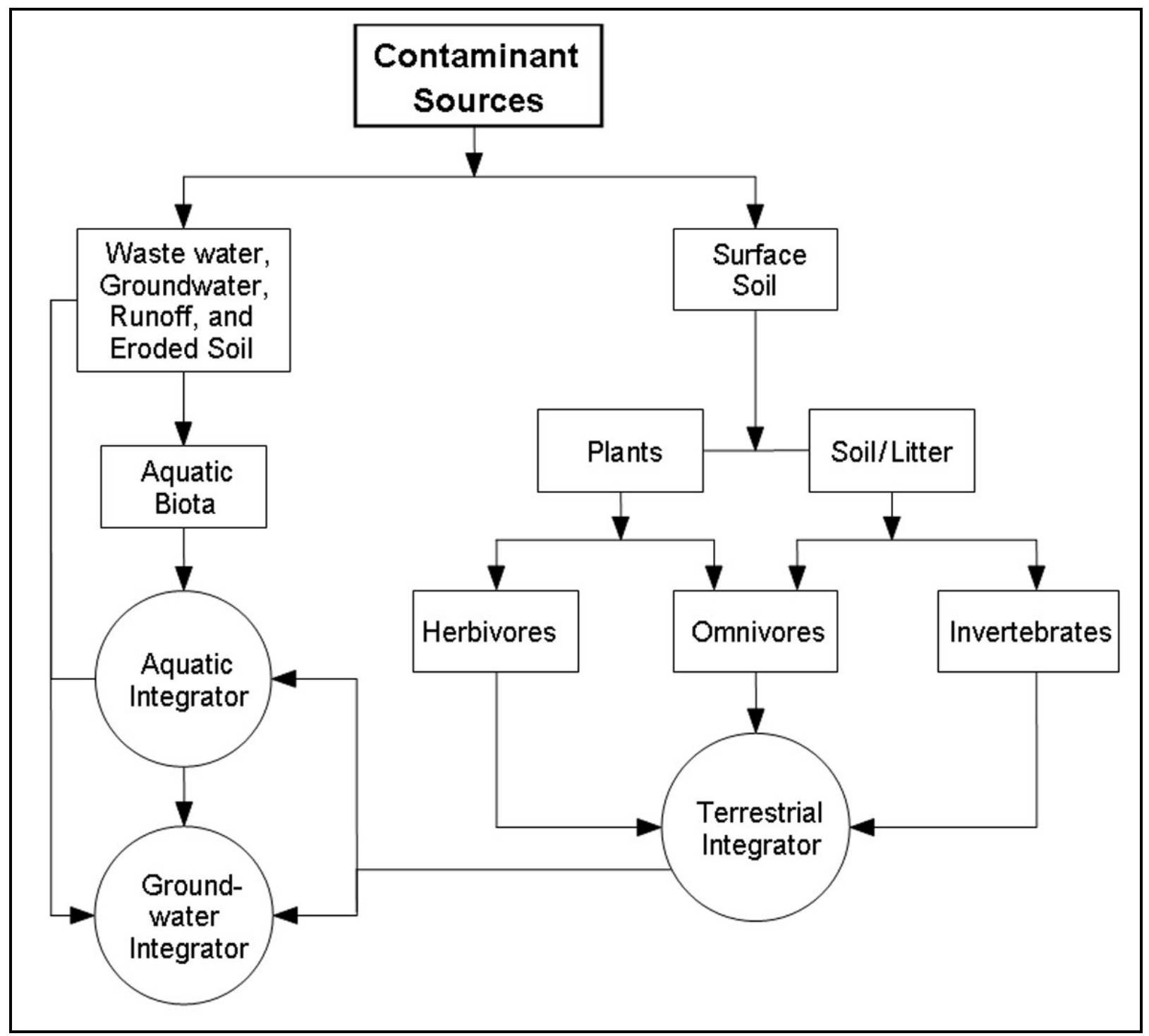

Figure 1. EPA Risk Assessment Framework (modified from Suter (1996))

Environmental impact assessment approaches. The techniques and approaches used in conceptual models have benefited from the methods developed in response to the National Environmental Policy Act's (P.L. 91-190) requirements for communication of technical issues, examination of all possible impacts, and identification of impacts' significance. Environmental 
impact assessment methods have provided mechanisms to determine "effect/no effect," delineate secondary and higher order impacts, and quantify or rank the magnitude of effects (Canter 1986). For conceptual models, these tools provide familiar procedures to systematically consider possible interactions among resources, processes, and human and natural forces, possibly not considered previously. Interaction matrices, checklists, and impact networks from impact assessment efforts have assisted in determining the details of conceptual model interactions. Figure 2 shows an impact tree, one of the assessment tools used to identify direct and secondary impacts of freeway construction through an urban area (Council on Environmental Quality (CEQ) 1997).

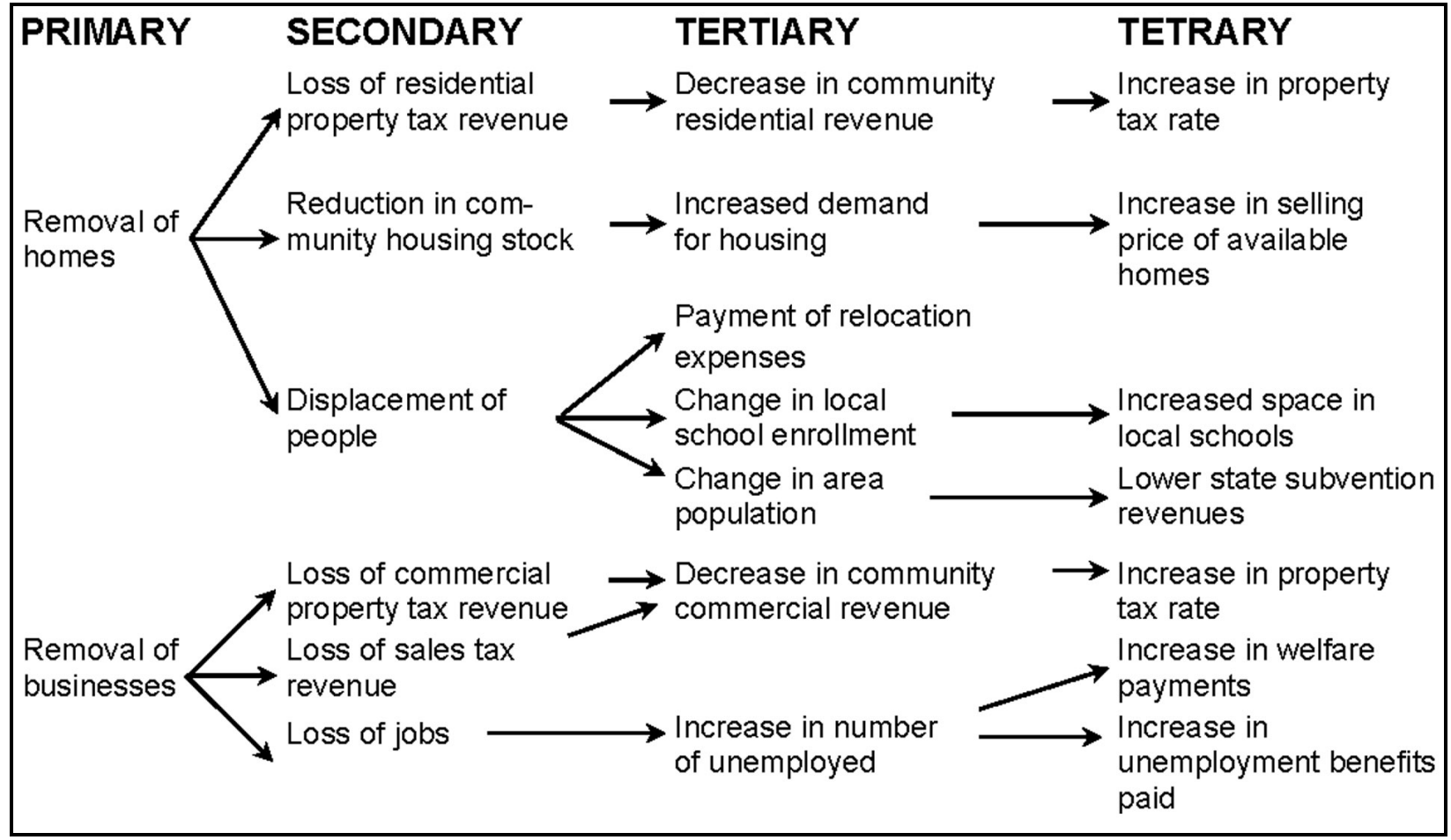

Figure 2. Impact tree showing higher order impacts resulting from freeway construction through an urban environment (CEQ 1997)

Systems approaches. Recent years have seen an increased appreciation for the complexities, interconnectedness, and hierarchical nature of natural and human systems. The "systems approach" has become a readily recognizable vehicle for discussion of topics, problems, or issues among individuals with different expertise and experience. Contributions and understandings from energy and systems ecology made popular by Howard T. Odum on the ecological side (Odum 1983), and from systems and operations research on the engineering side, have given rise to system applications in physical, biological, and social disciplines. These system approaches have provided individuals from numerous disciplines with experience in and an appreciation for conceptual analysis.

Recent Developments. The emphasis on watershed, landscape, and ecosystem approaches to planning has given rise to the need for methods for characterizing and explaining resources and processes that were formerly addressed and modeled only on a site-by-site basis (Bohn and 
Kershner 2002). The three sources — risk framework, impact assessment methods, and systems approaches - have contributed to the present formulation of conceptual models for ecosystem applications. In the three circumstances described below, an approach is required that encourages thinking about interactions of system components at different spatial levels and spatial scales, and for multiple users and functions. Circumstances like these-where entire systems must be understood well enough to take reliable and reasoned actions - are the circumstances for which conceptual models are best suited.

System-wide processes. Consider the situation where bald eagle deaths begin occurring at reservoirs in different geographic regions of the southern United States (e.g., Arkansas and South Carolina). Investigations indicate the disease source is related to algae growing on aquatic vegetation that is eaten by coots, a favorite prey of the eagles. Efforts to estimate the possible loss of the eagle population require first understanding the links between the algae, aquatic plants, and ingestion up the food chain at a reservoir, and secondly identifying interaction and transport mechanisms between geographically distant reservoirs.

Multiple users, stakeholders, or disciplines. Consider the management of a multiple-use reservoir. In recent years, the invasion of nuisance aquatic species has brought to the forefront the multiple and sometimes conflicting uses and demands made on natural resource management. Managing aquatic vegetation to maximize use begs the questions "use by whom"? and "what level of nuisance plants is acceptable"? Accommodating lake users-water contact recreation, e.g., water skiers, anglers who prefer some level of vegetation for fishery habitat, and homeowners who require lake access from their property - requires development of a mechanism to understand how the users interact with aquatic plants and how these uses affect other users. Aquatic plant management requires incorporating what happens in the lake as well as upstream, and in the floodplain.

Trade-offs among system components, structures, or functions. Wetland ecosystems provide an example of possible tradeoffs. Wetland restoration may be designed to reinstitute a range of important wetland structures and functions. Establishing structural connections from the wetland to previously cut-off tributaries, backwater areas, and outflows allows aquatic species to access the previously cut-off areas, increasing migration and supporting reproduction in these areas. This connectivity and interspersion of habitat structure responds to changes in the flow of water provided naturally or through management. Restoration of long-term water storage in wetlands helps retain flood flows, sustains deep-water habitat, and reduces the flow of water that maintains habitat connectivity to the main channel. As the water storage capacity increases, the structural connectivity function decreases, causing the migratory and reproductive functions to decrease. Thus, in operating a restoration project, the change in functions can be in opposite directions. In this case, the capacities for water storage and for fishery habitat connectivity must be balanced or traded off, so that a single water control strategy can be designed.

The Upper Mississippi Ecosystem Conceptual Model. Some conceptual models are more complex than the above circumstances demonstrate. The Upper Mississippi Ecosystem 
Conceptual Model (Lubinski and Barko 2003) ${ }^{1}$ is being developed to provide an adaptive management framework for management actions and to communicate complex ecological interactions to the public and resource managers. The conceptual model approach resulted from a recommendation by the National Research Council to evaluate in a holistic manner the environmental impacts of the Upper Mississippi River-Illinois Waterway (UMR-IWW) on the sustainability of the entire river system, rather than limit the evaluation to the impacts of increased navigation traffic alone. The recommendation resulted in restructuring of the Upper Mississippi River-Illinois Waterway System Navigation Feasibility Study to focus on sustainability of the economic uses and ecological integrity of the Upper Mississippi River System.

With the navigation study's broadened focus on sustainability, it became important that a common framework be developed for understanding the ecological functioning of the system, the effects of management actions on the system, and the objectives and needs of stakeholder and user groups. The different stakeholder groups - navigation, recreation, conservationneeded a single model on which to base input and evaluations on management efforts for the system. To develop a comprehensive understanding of the river system, an Expert Panel was formed from the Corps Districts (St. Paul, Rock Island, and St. Louis), the U.S. Army Engineer Research and Development Center Environmental Laboratory, U.S. Fish and Wildlife Service, U.S. Geological Survey, two universities, and the Missouri Department of Conservation.

The Expert Panel developed a series of conceptual models for the Upper Mississippi River and for the management actions. Figure 3 is a simplified version of the overall river model. The overall model (Figure 3) incorporates the natural river system "System Framework" (upper left), which controls fluxes of matter and energy (drivers) that produce first-order changes in the system (the stressors) which can be affected by management. Stakeholder objectives are used to formulate potential management actions into plans (upper right). The Essential Ecosystem Chacteristics (EEC) (lower left) are the categories of ecological structure and function for the system, and are used to identify the types of second-order changes in the system. For ongoing operation of the system, monitoring of endpoints (lower right), adaptive management, and feedback to the objectives are included in the model. In addition to the overall system model, the Expert Panel developed a series of conceptual models for selected management actionsartificial island construction, fish passage improvement at dams, removal (dredging) of backwater plugs, creation of wildlife sanctuary areas, and water level drawdown.

\section{AN APPROACH TO CONCEPTUAL MODEL DEVELOPMENT FOR}

ENVIRONMENTAL SYSTEMS: The approach to conceptual model development outlined below is based on documentation of models developed for a range of applications. The approach provided has six steps meant to be followed sequentially, with ongoing review and reiteration. Each step is accompanied by an illustration from the literature. Review by outside experts or knowledgeable individuals not involved with development can assure that the system model includes relevant constituents. Finally, a willingness to reiterate the process to refine or develop consensus on structures or relationships is always necessary.

\footnotetext{
${ }^{1}$ The conceptual model is included in the Environmental Science Panel Report, part of the series of Navigation Study Reports produced as part of the UMR-IWW study.
} 
Step 1: Identify the Objectives and Uses of the Model. Conceptual models may be developed as part of a planning study or during investigations for operations, monitoring, and mitigation plans. Objectives for constructing the conceptual models may be different from the objectives of a planning study and other investigations. The individuals responsible for conceptual model development must state the objectives and uses of the model. This normally means clarifying or operationalizing the reasons given for the model and its use. The time spent on this first task may be indicative of the range of consensus or experience, interest, and expectations of the team members, stakeholders, and agencies involved. The objectives and uses are highly related so that in some cases, they may appear to be identical.

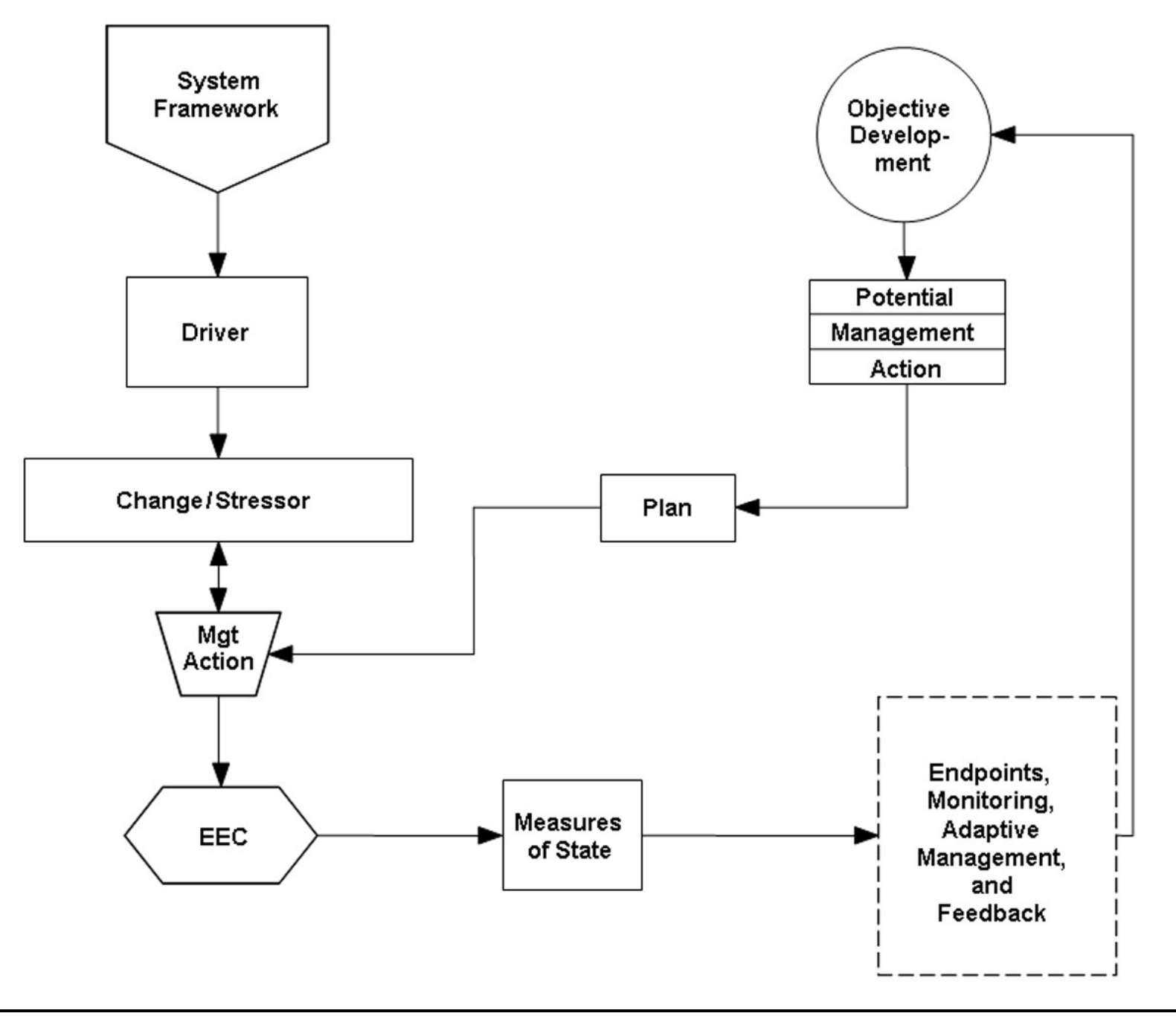

Figure 3. Simplified version of the conceptual model for sustainable navigation and ecological functioning of the UMR-IWW (Lubinski and Barko 2003)

Objectives may include:

- Identify influence or cause-effect relationships.

- Communicate technical or complex issues or systems to agency partners and stakeholders. 
- Organize system components - relationships of the system structures, showing interactions, flows, and processes - to identify significant or critical attributes.

Uses of the model are:

- Assessment and evaluation of changes to the system - range of natural variability; trends in model constituents, effects of planned management actions, alternatives, and scenarios; and use of the model as a simulation tool. Assessment and evaluation may support or disprove assumptions or hypotheses about the system, and the cause-and-effect relationships.

- Providing an organizational framework for integration of input from multiple disciplines.

- Evaluation of representative elements for significant effects on system resources and integrity, stress, and risk.

Development of objectives and use statements is guided by the following questions:

- Who will use, run, or implement the model?

- Who has to understand the output or results of the model?

- What level of detail is needed to meet the objectives of the model?

Clear statement of objectives and uses should provide the team members with insights on the focus and configuration of the conceptual model. The Everglades provides an example. Determining how effective Everglades wastewater management efforts are for improving lake water quality in Lake Okeechobee, i.e, hypothesis testing (Figure 4) entails monitoring of water quality performance measures, specifically phosphorus, nitrogen, and algae levels, to prove, disprove or refine hypotheses about the relationship of those levels to water quality. These performance measures will help understanding of, for instance, how the use of upstream settling ponds as a management measure in the Central and South Florida (C\&SF) Project causes changes in phosphorus, nitrogen, and other inputs that influence the condition of ecosystem resources and achievement of environmental objectives.

For the Okeechobee, the focus is on understanding changes throughout and along the system, requiring modeling of flows and transformation of nutrients, chemicals, plants, and water regime. After a period of monitoring, the pathways of interaction may be disproved, become clearer, or the significant or dominant components or processes may emerge. This allows revision of the conceptual model. In other cases, model objectives and uses may focus the effort more broadly or more narrowly on the endpoint or target condition. An example of a more narrow focus is the use of gravitational circulation to identify how physical changes in Suisan Bay affect the target condition. Continued data collection may confirm, disprove, or clarify relationships, resulting in revisions (Figure 5).

The presentation of the conceptual model and complexity are evidenced by the objectives and uses. The word model used for gravitational circulation (Figure 5) fulfills the objectives to identify the character of the relationships. Evaluation of more complex systems, with flows of energy and materials between system levels, requires more detailed specification and quantification of interactions and responses. Table A2 (Appendix A) summarizes possible types of conceptual models (modified from Jorgensen (1988) and Tighe and O'Neil (in preparation)). 


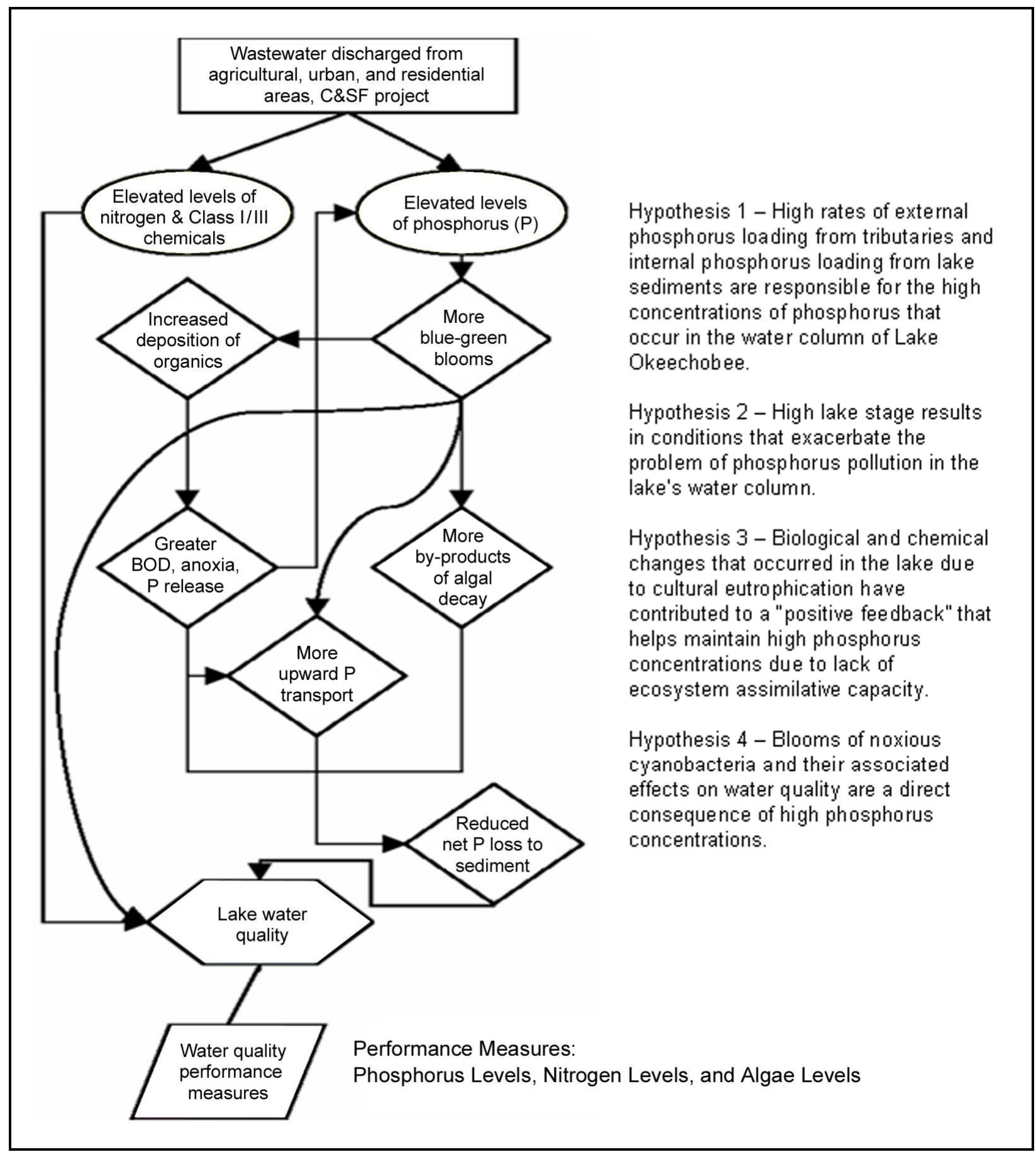

Figure 4. Lake Okeechobee Ecosystem Model (Havens 1999) 


\begin{tabular}{|l|l|l|}
\hline Feature & Existing Conceptual Model & Revised Conceptual Model \\
\hline $\begin{array}{l}\text { Gravitational circulation } \\
\text { strength }\end{array}$ & $\begin{array}{l}\text { Water depth, density gradient, and } \\
\text { spring/neap cycle are not } \\
\text { considered }\end{array}$ & $\begin{array}{l}\text { Increases with water depth and } \\
\text { longitudinal density gradient, and } \\
\text { is greater during neap tides than } \\
\text { during spring tides }\end{array}$ \\
\hline $\begin{array}{l}\text { Gravitational circulation } \\
\text { location }\end{array}$ & $\begin{array}{l}\text { Surface salinity is } 1 \text { to } 6 \mathrm{psu} \\
\text { (psu = practical salinity unit) }\end{array}$ & $\begin{array}{l}\text { Geographically fixed when a } \\
\text { longitudinal density gradient is } \\
\text { present, independent of salinity } \\
\text { (when salinity is greater than zero) }\end{array}$ \\
\hline $\begin{array}{l}\text { Estuarine turbidity } \\
\text { maximum }\end{array}$ & $\begin{array}{l}\text { Formed by gravitational circulation } \\
\text { Where surface salinity is 1 to } 6 \text { psu, } \\
\text { shallow water adjacent to channel is } \\
\text { not considered }\end{array}$ & $\begin{array}{l}\text { Geographically fixed contribution } \\
\text { from wind-wave resuspension in } \\
\text { shallow water }\end{array}$ \\
\hline $\begin{array}{l}\text { Residual, near-bottom, } \\
\text { landward transport of } \\
\text { suspended sediment }\end{array}$ & Caused by gravitational circulation & $\begin{array}{l}\text { Can also be independent of } \\
\text { gravitational circulation }\end{array}$ \\
\hline
\end{tabular}

Figure 5. Gravitational Circulation and Estuarine Model, Suisan Bay, CA (Schoellhamer and Burau (1998))

Step 2: Delineate the Spatial and Temporal Scales or Boundaries of the Model. Ecological systems are inherently complex and hierarchical in character, and require that clear boundaries be specified for the model. Establishing the spatial and temporal requirements will clarify the structure and applicability of the model.

At what system level are we interested? A model developed at the scale of a river reach will differ from a model for the entire drainage basin in the type of forces acting on the system, physical and chemical processes incorporated, and the endpoints or target conditions. The spatial and temporal scales are in part determined by the objectives and uses of the model. Figure 6 is a model developed for the monitoring program of the Sierra Nevada Ecosystem Project (Manley et al. 1999). The Sierra Nevada model has three levels: Ecosystem, Sphere, and Process. For the Sierra Nevada, monitoring plans are developed for the Process level.

What are the requirements in the spatial extent of the system? In addition to the hierarchical specification, identifying the model scope or geographic limit is important. By identifying reference sites or a reference system comparable to the modeled system, the reference can identify break points or limits of spatial extent that can help establish boundaries for the conceptual model. These break points typically are determined by the origins of influential materials and forces operating in the area of concern. Distinct sources of air pollutants, for example, are traced back along pathways of air movement into the monitored area.

\section{Is the system homogeneous or are there major components or divisions of the system?}

Looking at the interactions within the system, it may make sense to organize the modeling effort into sub-models or subsystems, which interact through transfer of information or materials between major components. Other systems may be more integrated or homogenous. For 


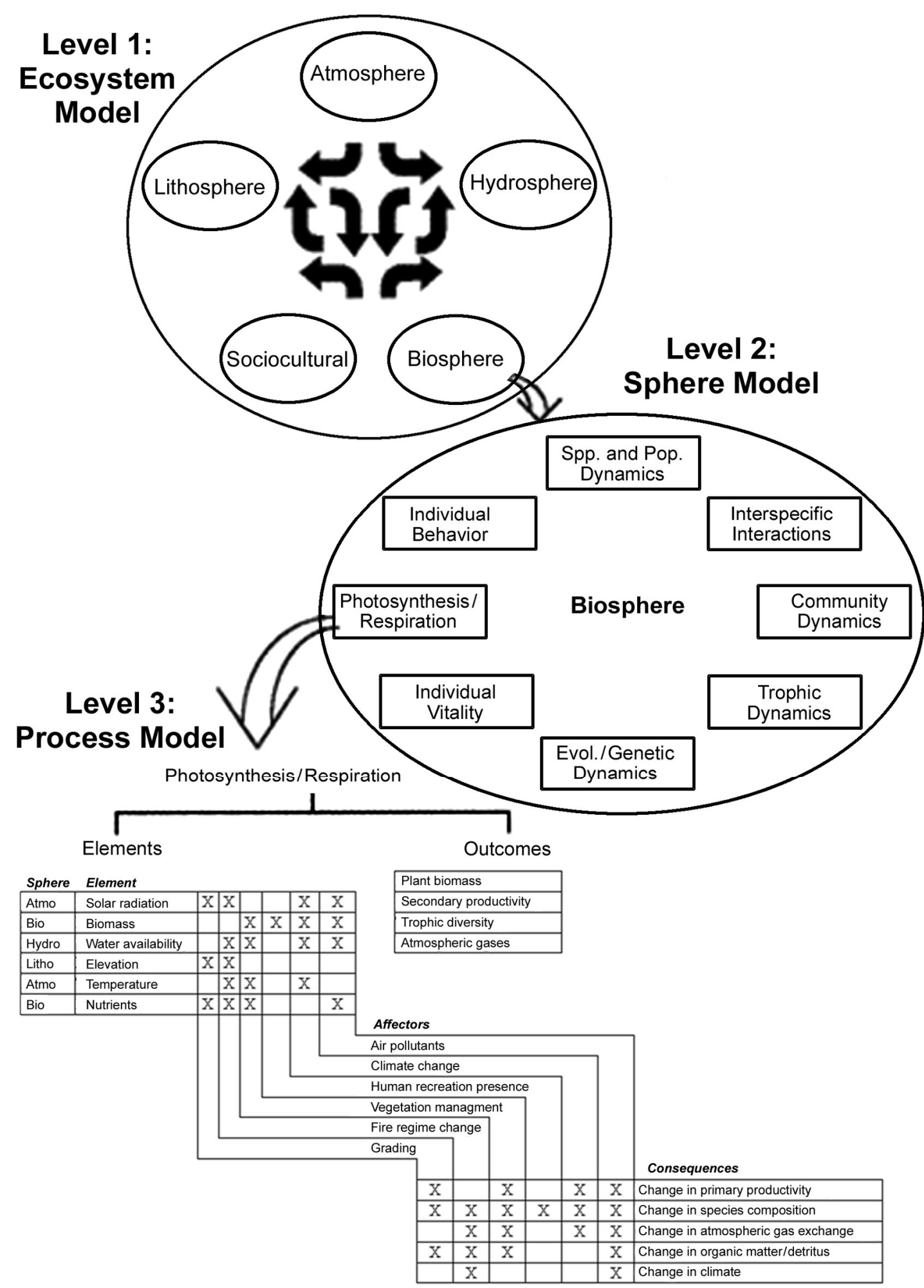

Figure 6. Conceptual model for monitoring in the Sierra Nevada ecosystem project (Manley et al. 1999) 
example, the Fire Island to Montauk Point Conceptual Model (U.S. Army Engineer Research and Development Center (USAERDC) and Harwell Gentile Assoc. 2001) was developed for five geographic subregions of the 83-mile reach, and ten major habitat types or communities.

What are the limits to the applicability of the model? If the model will be developed based on data from one region or area, but the intent is to apply it to a wider spatial domain, the extent to which the model structure and function can be applied must be addressed. A careful consideration of the available knowledge of the system and variability in the systems of potential applications may show that the range of generalization is more limited than expressed in the stated objectives and uses.

Does the model address a single existing or hypothetical point in time or is the model to be used for evaluating future conditions? In the temporal dimension, the objectives and use of the model may be to understand and represent the existing system as a static state. Other models may be for simulation over time, using the component states or measurements to mimic or trace step by step the behavior of the system (Grant et al. 1997) for different times or for different alternative management states.

As the modeling process progresses, the consistency of spatial and temporal boundaries with the stated objectives and uses should be questioned. It may be that the model cannot respond to meet the stated objectives and uses; changes or expansions to the objectives can be made to reflect this reality. Potential applications of the model may require analysis of effects over the project life cycle, whereas the model may have been formulated focusing on annual changes. Models for biological processes taking days may not meet the needs for the annual or seasonal management plans being formulated.

Spatial and temporal bounding of the model may reveal that there are interactions and transfers from what was perceived as a closed or static system (Grant et al. 1997). Discussion on how the system is structured-highly integrated or highly segmented - may reveal the need to limit or expand spatial or temporal dimensions.

Step 3: Identify the Structural Components of the System. The spatial and temporal delimitation for a model circumscribes the units or elements that make up the model, and reflects an understanding of hierarchical relationships and scope or applicability of the model. Abstracting from the real system those components that must be considered to address the user's questions (Grant et al. 1997) requires identifying the constituent elements and relationships. This can occur through fairly unstructured brainstorming or can be a highly systematic, iterative process.

For development of most conceptual models, the structural components and relationships have been identified by addressing a number of questions (Margoluis and Salafsky 1998), which are presented below. They are followed by a more detailed explanation of the Driver-StressorEndpoint formulation, which lends itself to a structured model-building process.

What is the target condition or conditions? This question addresses the end result of the model effort, e.g., what biotic or abiotic condition (structure and/or functions) will fulfill the 
objectives and uses. In south Louisiana, habitat types and changes in habitat types are the target conditions (Habitat Switching Module), evaluated using a set of desktop models (Figure 7). Depending on the objectives, target conditions can be somewhat more abstract, such as ecosystem health. For a model of contaminant movements, for example, risk to ecological health may be the target condition (Figure 1, USEPA 1998) indicated in structural and functional responses. Change in water regime to a wetland will cause a number of changes, but is the only concern loss of wetland acres, or is there also concern with the loss of associated wetland values modeled at a small scale? Both target conditions will result from water alterations to wetlands, but a model that assesses both function and value will add complexity (Figure 8). The target condition or endpoint question often leads to discussions on resource and impact significance and expectations of management measures.

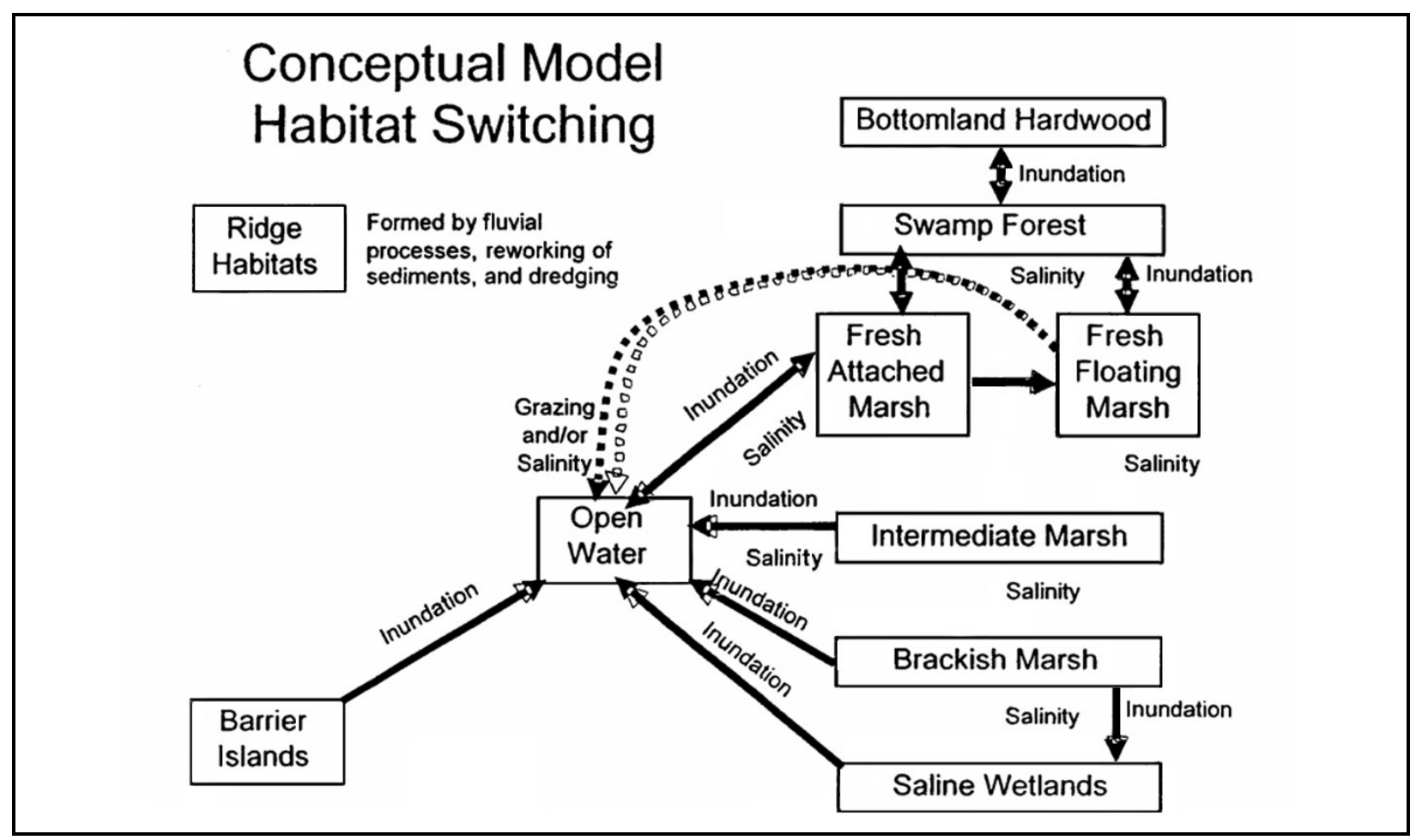

Figure 7. Desktop modeling for Louisiana coast (Visser et al. 2003)

How should the model be organized or configured? Organization of the model responds to the complexity of the system and requirements of the objectives and uses. The type of conceptual model used and the interactions included (Table A2) require different types of models with varying complexity of organization. Multiple levels of organization (Figure 6) may be needed to meet objectives or to explain the relationship of an endpoint or target condition to a higher organizational level. Organization of some models may be a matter of identifying "what we know and what's missing" or "what is the correct sequencing of these models so we use the information produced by each one?" Complexity of some systems may require computer programs and accounting systems to ensure all relevant components appear in the conceptual models. 


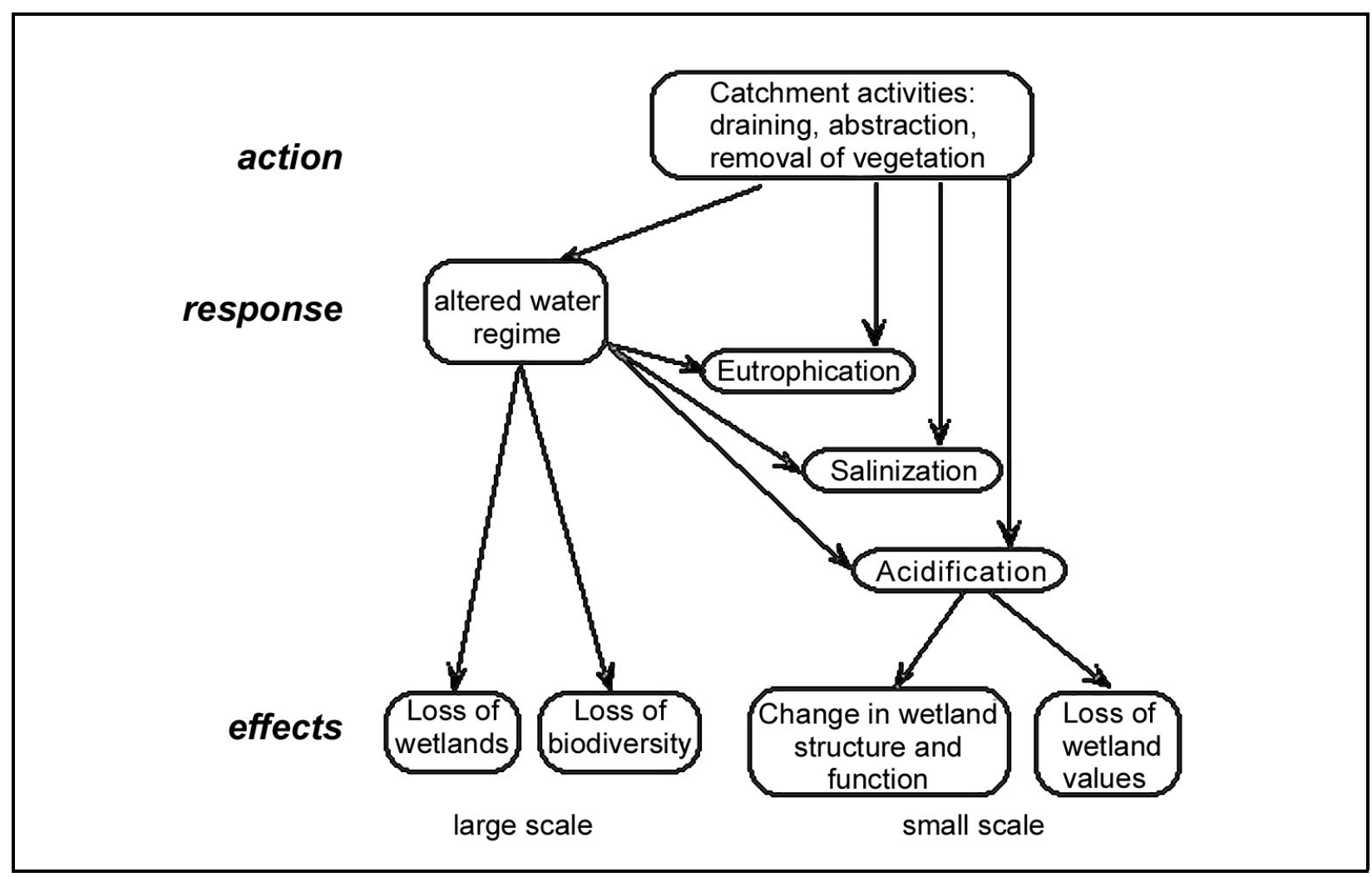

Figure 8. Effects of water regime changes on wetlands at organizational scales (Centre for Water Research 2001)

What are the relationships, interactions, and processes affecting the target conditions? The target conditions or endpoints are affected by factors through a series of steps. Assumed linkages are identified between the target condition and the factors and activities that cause or impact on the target condition. For example, damage to coral reefs results

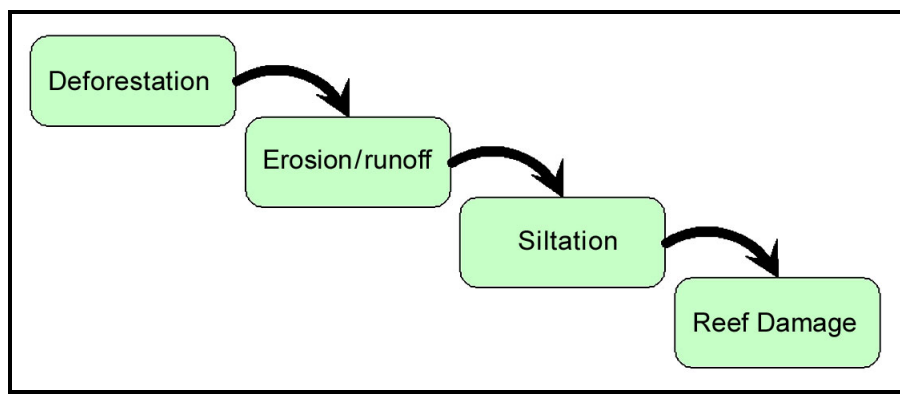

Figure 9. Establishing relationships to endpoints from a series of actions and processes (Figure 9, adapted from Margoluis and Salafsky 1998). The first factor in Figure 9, deforestation, results from natural forces or processes (disease, fire) and human actions (clearcutting) (Margoluis and Salafsky 1998). Identifying human activities and natural forces that cause the change factors in the system completes the question of "how does reef damage occur?" Looking at the factors leading to reef damage, characterization of the actions and processes can be qualitative (yes / no) or can be quantified with numerical or similar computational models.

How should these components and relationships be displayed? The above questions provide the basis for developing most conceptual models. In this case, the initial point was a target 
condition and working upwards to identify the drivers of the system, the natural and human forces. For other applications, the drivers of the system may be known, and the questioning would be to identify the changes resulting from the forces and the end results of the changes. The conceptual model components can be displayed in a number of ways (Table A2), and the nomenclature varies. The sources of contaminants in Figure 1 may be called stressors in other applications, and "Lake Water Quality" in the Okeechobee model fits the definition of endpoint, but is called an attribute in the Okeechobee model documentation (Havens 1999). It is important that the constructs used in the model make sense for the application and individuals involved with the model, and are suitable to the system processes and interactions being modeled.

The conceptual model constructs presented have been used in numerous applications and in a sense represent an evolution of thought and practice for conceptual models for environmental systems. The authors suggest four constructs-Drivers, Stressors, Essential Ecosystem Characteristics (EEC), and Endpoints —as an approach to conceptual modeling for system-wide assessments (Figure 10).

The stressors and endpoints are the constructs used for causes and effects in the system. The stressors - physical, chemical, and biological changes in the system - are the result of drivers, the natural and human forces at work in the system. Drivers serve as an organizational element, identifying the broad, system-wide forces. The other organizational construct is the EEC. The EECs serve to organize the categories of resources, structures, functions or processes. From the EECs, the endpoints can be identified. If it is clear what the endpoints will be, e.g., significant resources have been previously identified in the region, then there may not be a need to construct EECs. If there is open discussion on what is most important in the system, or what can serve as an indicator of changed endpoints, then EEC identification may be helpful.

\section{Conceptual Model Building Blocks - Drivers, Stressors, Essential Ecosystem Characteristics, and Endpoints}

- Drivers. Changes in natural systems are the results of forces on ecosystem structure and function. For conceptual models as defined here, these forces are called drivers. ${ }^{1}$ Drivers are the natural and anthropogenic processes that cause ('force') changes in environmental conditions, i.e., drivers identify the source or cause of the stressors in conceptual models. In some applications, such as in the Upper Mississippi model, only natural processes - the regimes - are considered as drivers; this distinction between natural and anthropogenic drivers may or may not be used in other models. The identification of drivers entails a

\footnotetext{
${ }^{1}$ Hereafter "conceptual models" will refer to the driver-stressor-EEC-endpoint conceptual model formulation.
} 
comprehensive description of the system of interest, identifying the forces that act on, influence, or cause changes in system environmental conditions. As such, the drivers are farreaching, universal, and non-quantified in nature.

Drivers are identified in the domain of the model (e.g., island in the river versus the river system) and objectives of the model (e.g., comprehensive or focused analysis). Drivers are identified as:

o Categories of natural and anthropogenic forces, such as the following examples (USAERDC and Harwell, Gentile Assoc. 2001):

- Natural drivers - storms, climate change, shoreline change, erosion and deposition.

- Anthropogenic drivers - changes in natural populations, development, agriculture and aquaculture, recreation, engineering, harvesting, nonindigenous and nuisance species and atmospheric deposition.

o Specification of particular natural and anthropogenic forces, such as the following from the Lake Okeechobee model (Havens 1999):

- Wastewater discharged from agricultural, urban, and residential areas.

- Increased sediments due to nutrient inputs, wind waves, and operation of water supply projects.

- Rainfall, evapotranspiration, and water supply deliveries.

- Control programs with herbicide, fire, and biological agents.

- Accidental or purposeful introductions of exotic species.

- Stressors. Stressors are the physical, chemical, and biological changes that result from natural and human-caused forces and effect other changes in ecosystem structure and/or function. Drivers can be considered first-order influences and stressors second-order influences in chains of cause and effect, where there are several links before the final effects on model endpoints. Stressors have associated time dimensions and usually can be quantified, e.g., nutrient loading rates. Stressors may affect a single resource or component, or the stressor may act on multiple ecosystem components, so that stressor effects may be limited or widespread.

\begin{tabular}{|c|c|c|}
\hline Factor & Drivers & Stressors \\
\hline Time & No time definition required & $\begin{array}{l}\text { Requires time dimension, context, } \\
\text { frequency, or periodicity. }\end{array}$ \\
\hline $\begin{array}{l}\text { Existence/Presence in } \\
\text { system }\end{array}$ & $\begin{array}{l}\text { Extant in system, either natural or } \\
\text { anthropogenic. }\end{array}$ & $\begin{array}{l}\text { Result from or caused by existing or } \\
\text { present entities, i.e., drivers. }\end{array}$ \\
\hline Quantification & Measurement not required. & $\begin{array}{l}\text { Measurement required to determine } \\
\text { consequences on endpoints. }\end{array}$ \\
\hline Thresholds & Affect all EECs. & $\begin{array}{l}\text { Affect one or more, but usually not all } \\
\text { EECs. }\end{array}$ \\
\hline Space & Exist over preponderance of system. & $\begin{array}{l}\text { Localized or limited in effect in the } \\
\text { system. }\end{array}$ \\
\hline Processes & Exist over preponderance of system. & $\begin{array}{l}\text { Localized or limited in effect on } \\
\text { endpoints or EECs. }\end{array}$ \\
\hline Synergism & Affect all endpoints or EECs. & Affect one or more endpoints or EECs \\
\hline
\end{tabular}


Stressors and drivers may be similar due to their characteristic of causing change in the system components. Table 1 compares drivers and stressors, which may help the reader in determining which to call a model component.

In the conceptual modeling process, the ecosystem state or condition of interest, i.e. endpoint, is affected by the stressors. Stressors may include any of a large array of possible structures and functions that may or may not be influenced by project implementation. For a nearshore benthic model, the stressors of habitat alteration, suspended sediments, and sealevel rise affect the endpoints of benthic infaunal community, benthic landscape mosaic, and sea turtles ${ }^{1}$ (USAERDC and Harwell Gentile Assoc. 2001). To identify potential stressors, the ecosystem endpoints may be examined to identify the physical, chemical, and biological changes that could affect the endpoints. If endpoints are uncertain or ill-defined, then drivers and EECs are examined to determine what changes could be produced by the drivers or could affect the EECs. The identification of stressors reflects the understanding of cause-andeffect relationships between environmental changes and endpoints. The description of stressors may require further specification or consideration of mechanisms or pathways responsible for ecosystem changes; for instance, the suspended sediments stressor may act through light attenuation, suffocation, or burial mechanisms to result in changes in the endpoints.

Examples of stressors are:

o Categories or types of changes - e.g., habitat alteration, sedimentation/turbidity, noise, solid wastes (USAERDC and Harwell, Gentile Assoc. 2001)

o Specified changes -from Lake Okeechobee (Havens 1999):

- Elevated levels of nitrogen- and ozone-depleting chemicals.

- Elevated levels of phosphorus.

- More resuspended sediments.

- Extremes in high lake stage.

- Extremes in low lake stage.

- Exotic and nuisance plants.

- Essential Ecosystem Characteristics (EEC). Two aspects of conceptual models require representing or characterizing the system of interest - identifying the drivers and describing the EECs. The EEC categories are an organizing device, showing the major components acted on or through which the stressors act to cause or result in endpoints in the system. The organizing categories reflect or respond to the model domain, the process being used for development or construction of the model, and the resources of interest. Making decisions on EEC categories or the approach to use is dependent on the technical disciplines involved and knowledge and understanding of endpoints to be measured. In Corps project and operations planning, endpoints can be any number of significant biotic and abiotic resources. Example system categories of EECs for the endpoints are:

o Resources (habitat resources, water resources, land and terrestrial resources) of the location, site, or study area applicable to the conceptual model.

o Categories or classifications of resource types (e.g., the subregions included in the Fire Island to Montauk Point study) (USAERDC and Harwell, Gentile Assoc. 2001).

\footnotetext{
${ }^{1}$ For illustration only, not a complete list of endpoints or stressors.
} 
o Ecosystem structural and functional categories, such as the following examples from the Sierra Nevada monitoring model (Manley et al. 1999).

- Individuals, populations, communities, or ecosystems.

- Physical, chemical, and biological processes.

- "Spheres" of processes - atmosphere, biosphere, hydrosphere, lithosphere, sociocultural sphere, and metaprocesses (nutrient cycling, hydrologic cycling).

- Ecosystem patterns and processes, such as the following: patterns of Landscape Conditions, Biotic Conditions and Chemical/Physical Characteristics, and processes of Hydrology/Geomorphology, Ecological Processes, and Natural Disturbances. These were the EECs recommended in the framework for assessing and reporting on ecological conditions (EPA Science Advisory Board 2002).

- Endpoints. The ecosystem structures or functions that are considered ecologically significant and important to the public (Harwell et al. 1999) are known as endpoints. Endpoints should be quantified and are often used in change assessment and monitoring. Each of the EECs has one or more endpoints. As a comparison, Table 2 displays the endpoints from three conceptual models.

\section{Table 2 \\ Examples of Endpoints}

\begin{tabular}{|l|l|l||}
\hline $\begin{array}{l}\text { Prairie Cluster Monitoring } \\
\text { Plan (Thomas et al. 2001) }\end{array}$ & $\begin{array}{l}\text { Lake Okeechobee (Havens } \\
\text { 1999) }\end{array}$ & $\begin{array}{l}\text { EPA Ecological Risk Assessment on } \\
\text { Terrestrial Ecosystem (Suter 1996) }\end{array}$ \\
\hline \hline Grassland plant communities & Lake water quality & Wildlife species \\
\hline Woodland plant communities & Fish and aquatic fauna & Threatened and endangered species \\
\hline Grassland bird communities & Native vegetation mosaic & Plant species \\
\hline Rare species populations & $\begin{array}{l}\text { Snail kite, wading birds, and } \\
\text { waterfowl }\end{array}$ & Pest populations \\
\hline
\end{tabular}

The objectives of the model, the EECs of the system, and understanding of the system will influence the specification of endpoints. Most systems will have a number of endpoints, generally distinct, but some may be interrelated, e.g., endpoints for fish and for invertebrates. An endpoint measure can be identified for each endpoint; that is, some method to measure the endpoint or change in the endpoint. For planning models, the endpoints usually are the significant resources for which project plans are formulated and evaluated, or the resources impacted by operations.

As mentioned above, the target condition or endpoint may be identified at different organizational levels. In the Fire Island model, categories of endpoints were identified for different ecological organization levels (Table 3). Determining whether a potential endpoint is significant is in part ecological and part a social question, whether the change is of sufficient type, intensity, extent, or duration to be important to society (USAERDC and Harwell Gentile Assoc. 2001). Selecting an endpoint that is ecologically significant enables the model to be used to distinguish changes that are important ecologically or publicly from changes that have little ecological importance or that represent the natural variability of the system. 


Table 3
Categories of Ecological Endpoints (USAERDC and Harwell Gentile Assoc.
2001)

- Assessment endpoints, performance measures, and indicators. The endpoints identified in conceptual models may be broad, such as "native vegetation mosaic," and as such measurement of the endpoint usually requires further specification. Often, for each endpoint or group of endpoints, another construct is needed to represent the endpoint measurement. These constructs are variously identified as assessment endpoints, performance measures, or indicators, depending on purposes, but all of them are indicators of output, responses to natural and/or human-caused changes in the modeled system. In Figure 4, for the endpoint of lake water quality in Lake Okeechobee, performance measures are identified with the parallelogram at the bottom of the figure.

Step 4: Identify the Sources of Change in the System. The changes that occur in ecological systems are often represented in conceptual models as information transfers (as in management measures) and flows of energy and materials, including nutrients and contaminants, through the system's structure. The system's structure is often organized by functional level in the system (e.g., primary producer, herbivore, carnivore, decomposer). Natural and humandeveloped processes, mechanisms, and pathways link changes in drivers to stressors and stressors to changes in EECs and to changes in endpoints. The changes or the pathways may be well-known or there may be uncertainty on the nature and quantification of the changes. For conceptual models showing relationships of subsystems or submodels, the changes are actually links for the interchange of data or information.

The approaches to identifying all changes run the gamut from brainstorming to the environmental assessment methods - interaction matrices and energy flow diagrams - and highly quantitative assessment and evaluation of change.

Examples of sources of change or linkages are:

- Identifying the sub-model outputs transferred to and used in processing of other sub-models (Figure 7) (Visser et al. 2003). 
- Quantifying the flows of material, nutrients, or energy through a system, e.g., the Lake Okeechobee model (Figure 4) (Havens 1999).

- Interaction matrices used to show driver: stressor (Figure 11) and stressor: endpoint (Figure 12) relationships for the Long Island ecosystems (USAERDC and Harwell Gentile Assoc. 2001).

Sources of change are typically identified by working back through the stressors from the endpoints. After the sources of changes are identified and the driver-stressor-EEC-endpoint relationships established, the development team should review the model structure for completeness, redundancy, and inclusion of components that may not be significant for the system. A way to do this is to select one or more stressors that are significant and follow the path in detail through to the endpoints. If there are endpoints not affected by the important stressors, consideration should be given to whether those components should be included for completeness or if removing them will affect the use of the model. Another way to examine the sources of change is to select a number of endpoints, and trace their existence or change to the stressors identified as responsible for producing the endpoints. If the endpoints are linked to all the identified stressors, then all the stressors are likely significant; if that is not the case, then combining or deleting some stressors may be indicated.

Step 5: Review the Model. Most conceptual models undergo development, revision, and further refinements so that the model possesses the highest level of accuracy of structure and relationship and is clear, understandable, and not confusing. At some point, model development should cease and a technical review be undertaken by knowledgeable individuals. Review of the model focuses on one primary question (the first question) and four diagnostic questions:

- How well, effective, efficient, and unambiguously does the conceptual model fulfill its stated objectives and uses?

- Does the system appear complete, or is it lacking in some part?

- Can all of the relationships be verified to be consistent with existing science or logic?

- Are the relationships and linkages clear and not redundant or overlapping?

- Is the applicability (geographic, technical) appropriate, unclear, or overstated?

Answering the primary question may also require the team to formulate scenarios or identify data sources to provide input to the model for evaluation of risk hypotheses, management actions, impact assessment, and operations changes.

Step 6: Implement the Model. To use, implement, or run the model to generate output, the following changes are identified:

- Changes in the model's drivers, stressors, and endpoints (Driver: Stressor Relationship (Figure 11)).

- Changes in the endpoints resulting from the stressors (e.g., Figure 12), or changes in the assessment endpoint, performance measures, or indicators, if applicable. 


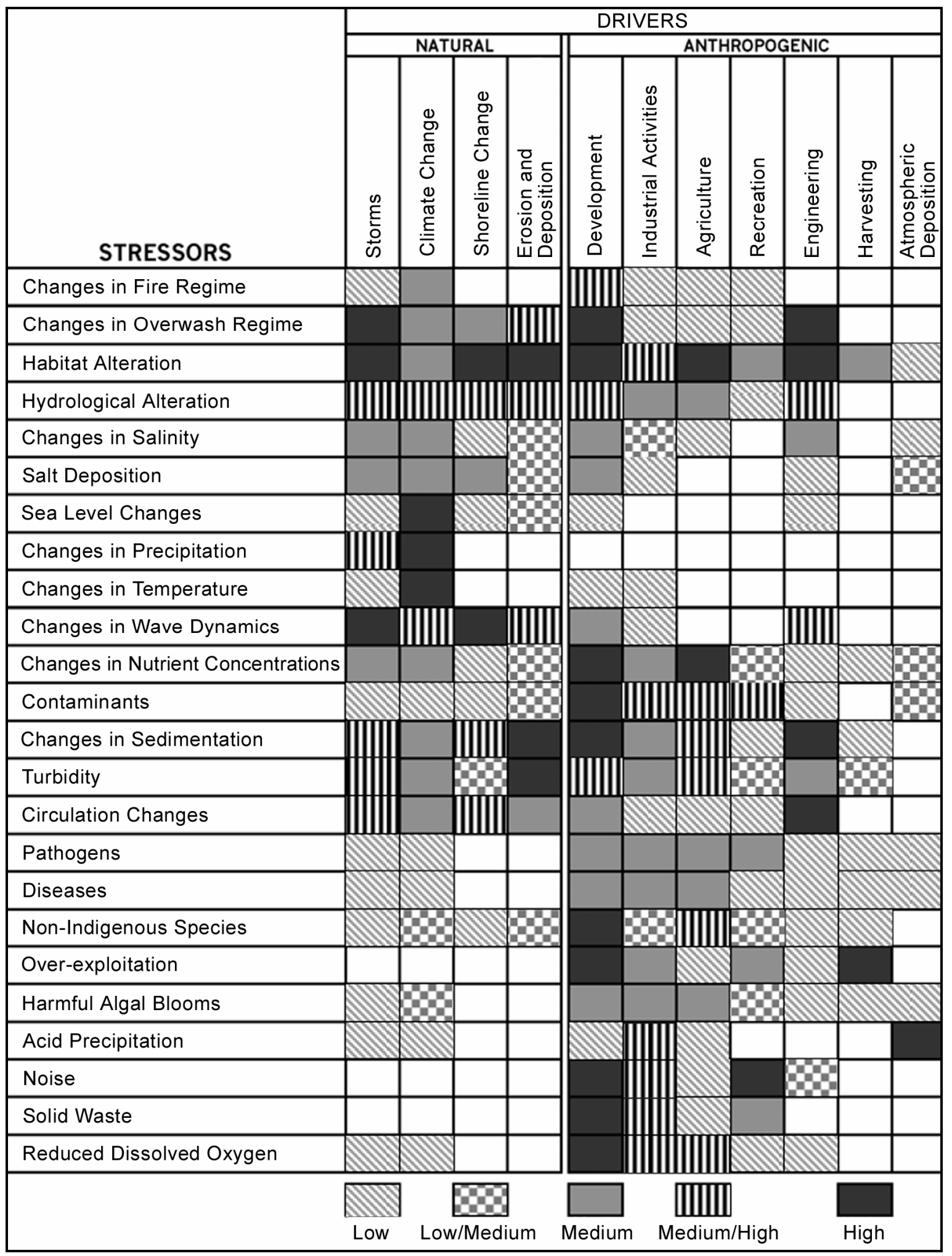

Figure 11. Driver: stressor interaction matrix for Fire Island to Montauk Point conceptual models (USAERDC and Harwell Gentile Assoc. 2001) 


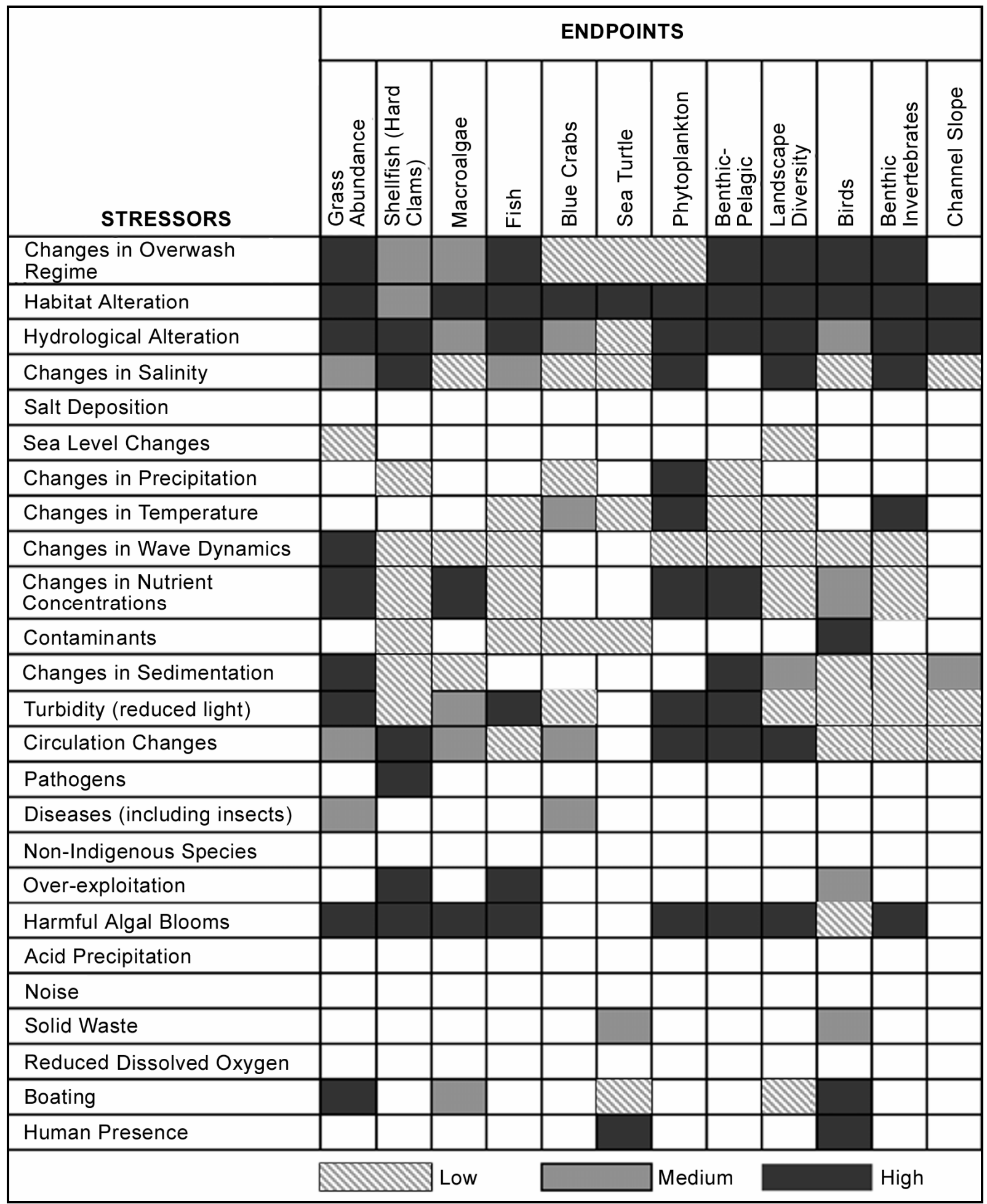

Figure 12. Stressor: endpoint interaction matrix for bay subtidal ecosystem, Fire Island to Montauk Point conceptual models (USAERDC and Harwell Gentile Assoc. 2001) 
Evaluating endpoint changes. The result of model implementation is the measurement of changes in system endpoints. The change in endpoints must be evaluated in terms of significance, as with the significance of effects in the planning process.

Evaluating model performance. After the model has been used, several performance questions should be considered in terms of possible revisions:

- Did the specification of drivers and stressors closely match the management measures or alternative components?

- Are there links or pathways of driver: stressor or endpoint: stressor relationships that were not affected? Is there a possibility the links are not important?

- Is there redundancy in the response of drivers, stressors, EECs, or endpoints? Does combining two or more make sense?

- Does the evaluation of endpoint changes make sense and provide decision-making or guidance capability?

The answers to these questions will provide indications of possible revisions to the model.

SUMMARY: Conceptual models are proving a useful tool for organizing, communicating, and facilitating analysis of natural systems. Stakeholder involvement in planning and project operation requires that agency decision-making be readily understood and accessible, no matter the complexity or uncertainties of the system. Conceptual models provide a vehicle for input from multiple disciplines, individuals, and agencies having interest or knowledge that affects understanding of an extant system or of likely changes.

The six-step approach presented here incorporates the necessary actions for conceptual model development and use for current model applications. Because conceptual models respond to the needs and requirements of an application, detailed or comprehensive guidance for all environmental applications is not possible. The six-step approach for conceptual models incorporates the necessary actions for development and use for current model applicationssystem structure and cause-effect relationships, communication, and significant or critical factor identification.

This technical note is a snapshot in time of the application of conceptual models to environmental systems. Future applications will produce refinements and innovations as new applications are completed and various agency and stakeholder needs are met. At some future time, another "snapshot" should be taken, showing expansion of the constructs presented here and innovations in conceptual modeling.

ACKNOWLEDGMENTS: The authors appreciate reviews and comments by Dr. Richard Cole, Institute for Water Resources and Drs. David Price and Steven Ashby, Environmental Laboratory, USAERDC. Ms. Renee' Caruthers, Computer Sciences Corp., Vicksburg, MS, provided graphic and processing support. The photo on page 1 is used by permission of the Great Lakes Indian Fish and Wildlife Commission, Odanah, WI.

POINTS OF CONTACT: This technical note was written by Jim E. Henderson and L. Jean O’Neil, Environmental Laboratory (EL), Engineer Research and Development Center (ERDC). 
For additional information, contact the Manager of the System-wide Modeling, Assessment, and Restoration Technologies (SMART) Program, Dr. Steven L. Ashby (601-634-2387, Steven.L.Ashby@erdc.usace.army.mil).This technical note should be cited as follows:

Henderson, J. E., and O’Neil, L. J. (2004). “Conceptual models to support environmental planning and operations," SMART Technical Notes Collection, ERDC/TN SMART-04-9, U.S. Army Engineer Research and Development Center, Vickburg, MS.

\section{REFERENCES}

Baron, J. S., Poff, N. L., Angermeier, P. L., Dahm, C. N., Gleick, P. H., Hairston, N. G., Jr., Jackson, R. B., Johnston, C. A., Richter, B. D., and Steinman, A .D. (2002). "Meeting ecological and societal needs for freshwater," Ecological Applications 12(5), 1247-1260.

Bohn, B. A., and Kershner, J. L. (2002). "Establishing aquatic restoration priorities using a watershed approach," J. of Environmental Management 64(4), 355-363.

Canter, L. W. (1986). Environmental impact of water resources projects. Lewis publishers, Chelsea, MI.

Centre for Water Research. (2001). "Using conceptual models as a management tool," University of Western Australia, Perth, Western Australia.

Council on Environmental Quality. (1997). “Considering cumulative effects under the National Environmental Policy Act," Washington, DC.

Dortch, M. S. (2001). Army Risk Assessment Modeling System. Assessment and management of environmental risks, cost efficient methods and applications, ed. by Igor Linkov and Jose Palma-Oliveira, published in cooperation with NATO Scientific Affair Division, Kluwer Academic Pub., Amsterdam, Netherlands http://www.wes.army.mil/el/arams/arams.html

Grant, W. E. (1986). System analysis and simulation in wildlife and fisheries sciences. John Wiley, New York.

Grant, W. E., Pederson, E. K., and Marin, S. L. (1997). Ecology and natural resource management, system analysis and simulation. John Wiley, New York.

Harwell, M. A., Myers, V., Young, T., Bartuska, A., Gassman, N., Gentile, J. H., Harwell, C. C., Appelbaum, S., Barko, J., Causey, B., Johnson, C., McLean, A., Smola, R., Templet, P., and Tosini, S. (1999). "A framework for an ecosystem integrity report card," Bioscience 49(7), 543-556.

Havens, K. E. (1999). “Lake Okeechobee conceptual ecosystem model,” South Florida Water Management District, http://glacier.sfwmd.gov/org/wrp/wrp_okee/2_wrp_okee inlake/conceptual_model.pdf

Jorgensen, S. E. (1988). Fundamentals of ecological modeling. Elsevier Science Publishers, New York.

Jorgensen, S. E., Halling-Sorensen, and Nielson, S. N. (1996). Handbook of environmental and ecological modeling. CRC Press, Boca Raton, FL.

Lubinski, K. S., and Barko, J. W. (2003). "Mississippi River-Illinois Waterway System navigation feasibility study: Environmental science panel report,” ENV Report 52, U.S. Army Engineer Districts, Rock Island, St. Louis, and St. Paul. http://www2.mvr.usace.army.mil/umr-iwwsns/documents/ENV\%20Report\%2052.pdf

Manley, P. N., Stuart, C. M, Lind, A. J., Plymale, B. L., Zielinski, W. J., Keane, J. J., Brown, C. and Napper, C. O. (1999). "Chapter 8: Monitoring ecosystems in the Sierra Nevada: the conceptual model foundation." Sierra Nevada National Forest land management planning monitoring strategy development. U.S. Forest Service, Pacific Southwest Region and Station, Albany, CA. 
Margoluis, R., and Salafsky, N. (1998). Measures of success: Designing, managing and monitoring conservation and development projects. Island Press, Washington, DC.

Odum, H. T. (1983). Systems ecology, an introduction. John Wiley, New York.

Public Law 91-190. (1969). National Environmental Policy Act.

Schoellhamer, D. H., and Burau, J. R. (1998). "Summary of findings about circulation and the estuarine turbidity maximum in Suisun Bay, California," U.S. Geological Survey Fact Sheet FS-047-98, U.S. Geological Service, San Francisco, CA. http://sfbay.wr.usgs.gov/access/suisunbay/dschoell/summary.html

South Florida Water Management District. (1999). "Watershed management-ecological components." http://www. sfwmd.gov/org/wrp/wrp evg/2_wrp_evg_eco/2_wrp_evg_eco.html

Suter, G.W., II. (1996). "Guide for developing conceptual models for ecological risk assessments.” ES/ER/TM186, U.S. Department of Engergy, Oak Ridge, TN.

Thomas, L. P., DeBacker, M. D., Boetsch, J. R., and Peitz, D. G. (2001). “Conceptual framework, monitoring components and implementation of a NPS long-term ecological monitoring program - Prairie Cluster prototype program status report," National Park Service, Republic, MO. http://www.nature.nps.gov/im/monitor/ PCConceptDesign.doc

Tighe, R. E., and O’Neil, L. J. (in preparation). "Network and system diagram models for ecological processes and systems," SMART technical note in preparation. U.S. Army Engineer Research and Development Center, Vicksburg, MS.

U.S. Army Engineer Research and Development Center and Harwell Gentile and Assoc. (2001). "Conceptual model for coastal Long Island ecosystems: Fire Island to Montauk Point reformulation study,” Draft report, Vicksburg, MS.

U.S. Environmental Protection Agency (USEPA). (1992). "Framework for ecological risk assessment," EPA/630/R-92/001, Washington, DC.

U.S. Environmental Protection Agency (USEPA). (1998). "Guidelines for ecological risk assessment," EPA/630/R-95/002F, Washington, DC.

U.S. Environmental Protection Agency (USEPA) Science Advisory Board. (2002). A framework for assessing and reporting on ecological condition: an SAB report. EPA-SAB-EPEC-02-009, Washington, DC. http://www.epa.gov/sab.

Visser, J. M., Steyer, G. D., Shaffer, G. P., Hopner, S. S., Hester, M. W., Reyes, E., Keddy, P., Mendelssohn, I. A., Sasser, C. E., and Swarzenski, C. (2003). "Louisiana coastal area, habitat switching models," U.S. Army Engineer District, New Orleans, LA.

NOTE: The contents of this technical note are not to be used for advertising, publication, or promotional purposes. Citation of trade names does not constitute an official endorsement or approval of the use of such products. 


\section{APPENDIX A: TYPES OF CONCEPTUAL MODELS}

Table A1 - Applications of Conceptual Models in Environmental Planning

Table A2 - Types of Conceptual Models 


\begin{tabular}{|c|c|c|c|c|c|c|c|}
\hline & 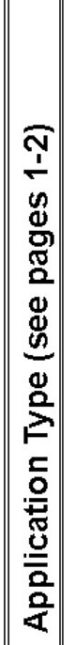 & 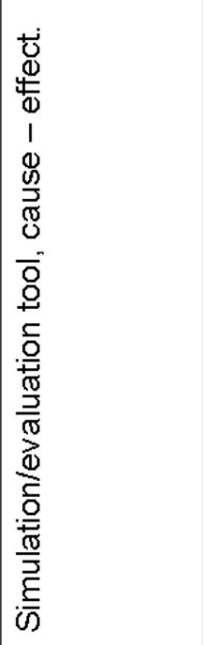 & 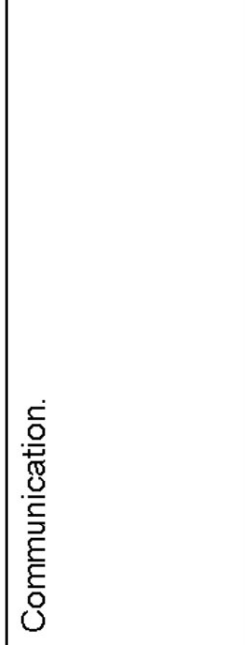 & 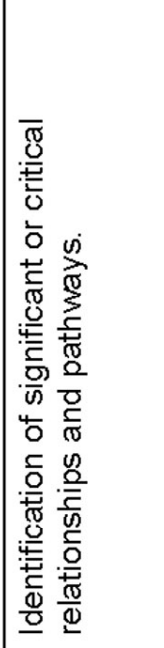 & 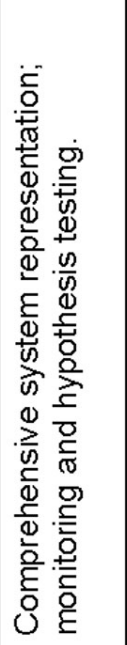 & 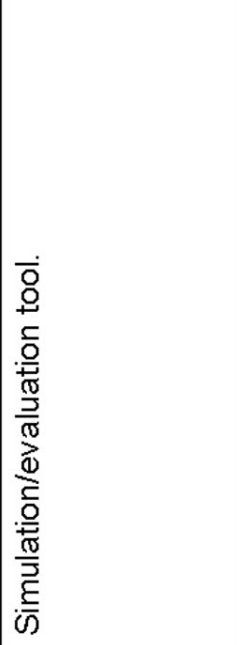 & 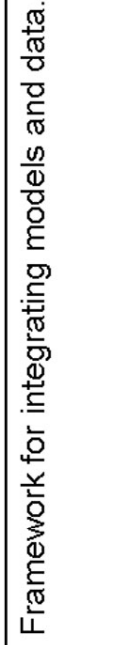 \\
\hline 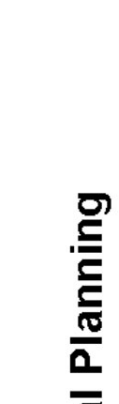 & 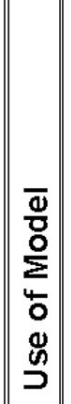 & 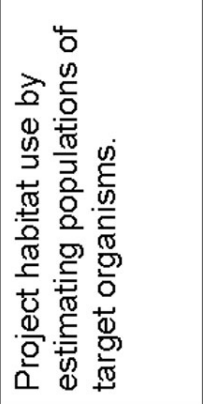 & 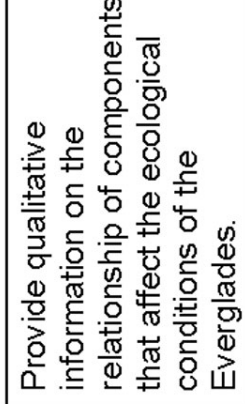 & 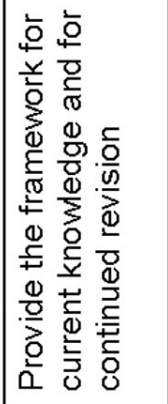 & 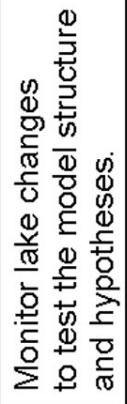 & 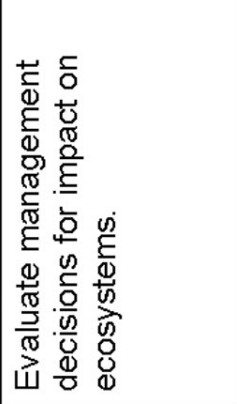 & 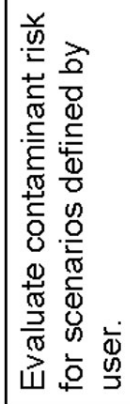 \\
\hline 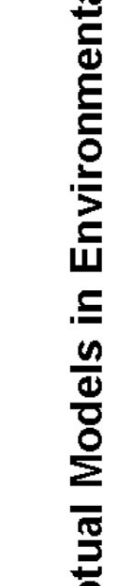 & 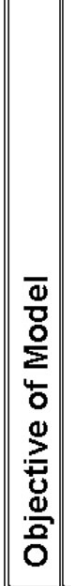 & 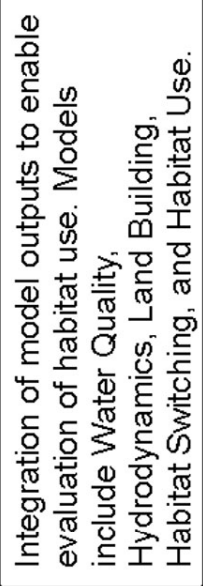 & 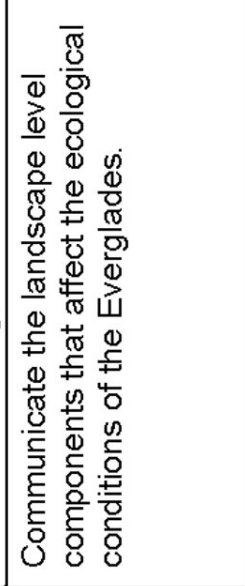 & 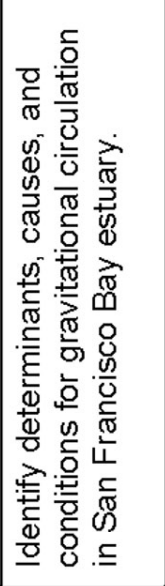 & 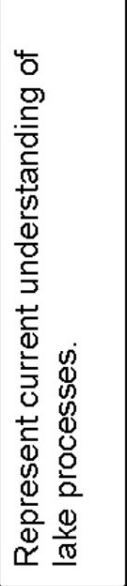 & 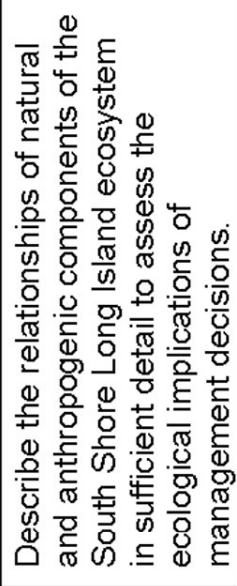 & 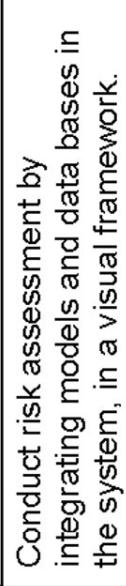 \\
\hline 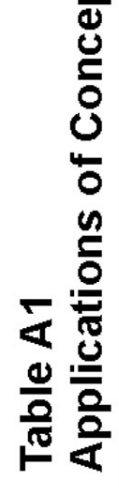 & $\mid$\begin{tabular}{|l||}
$\overline{\mathbf{d}}$ \\
$\frac{\mathrm{o}}{2}$ \\
$\overline{2}$
\end{tabular} & 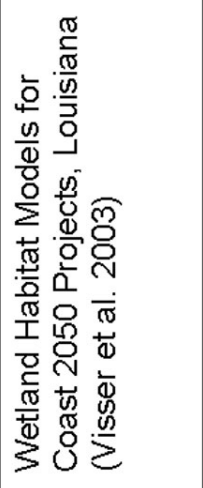 & 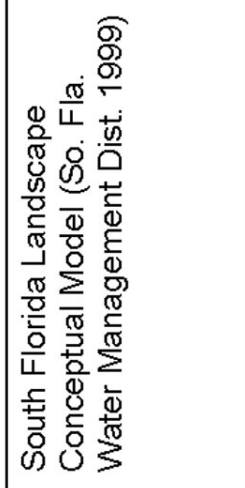 & 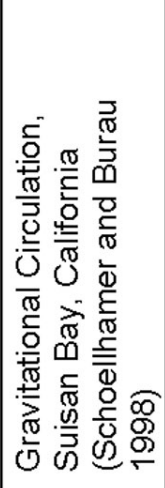 & 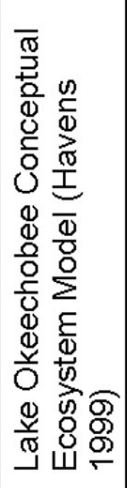 & 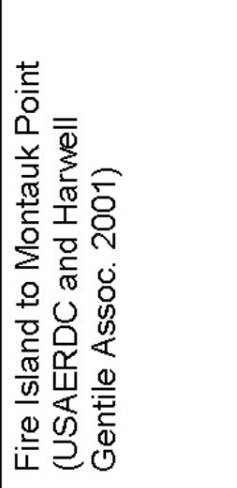 & 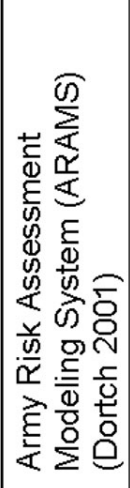 \\
\hline
\end{tabular}




\begin{tabular}{|c|c|c|c|c|c|c|c|c|c|c|c|}
\hline \multirow{4}{*}{ 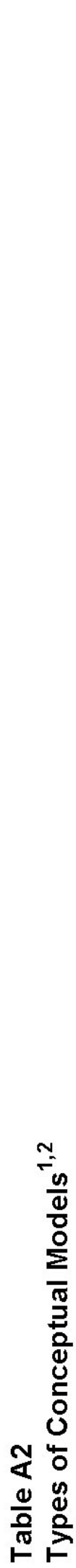 } & 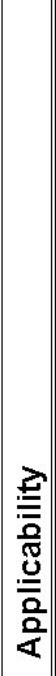 & 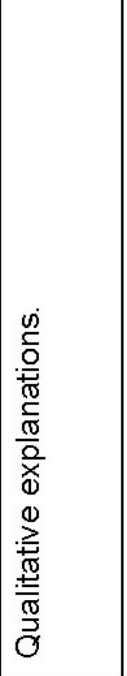 & 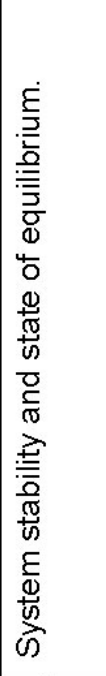 & 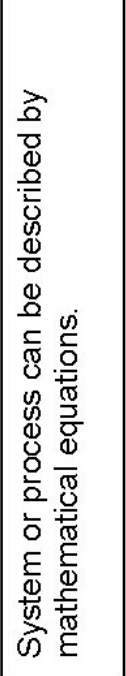 & 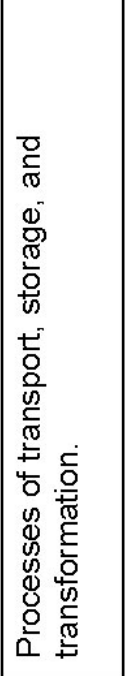 & 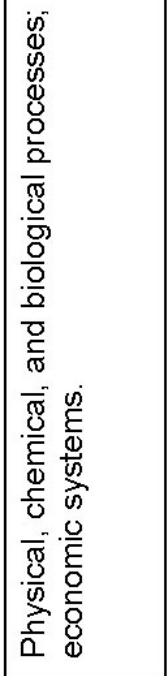 & 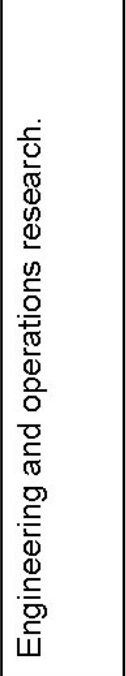 & 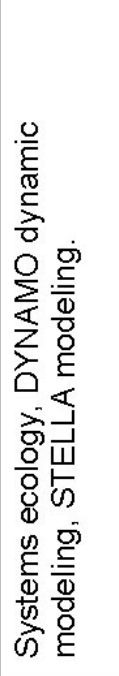 & 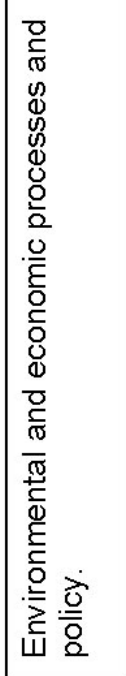 & 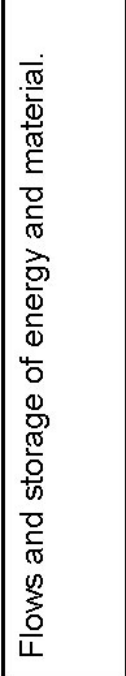 & \multirow{4}{*}{ 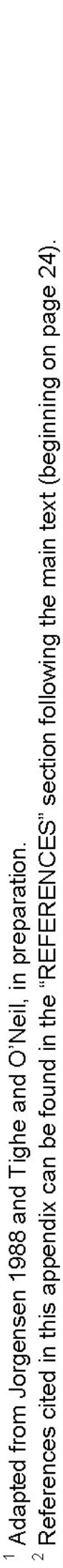 } \\
\hline & 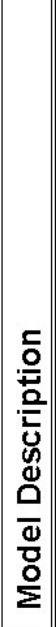 & 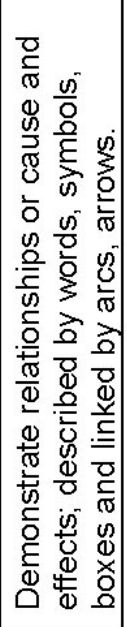 & 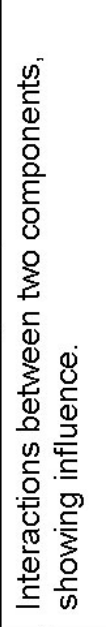 & 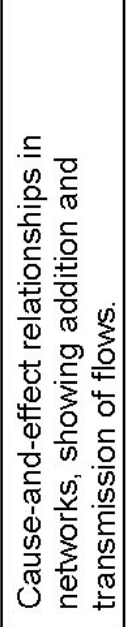 & 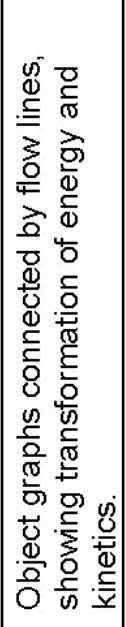 & 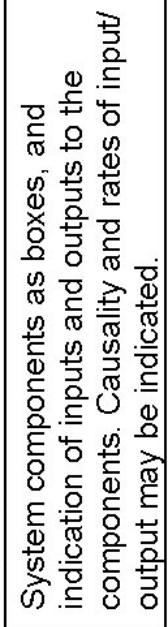 & 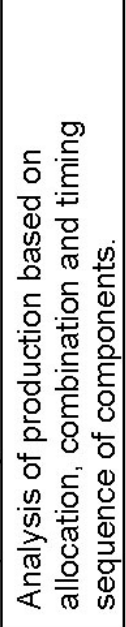 & 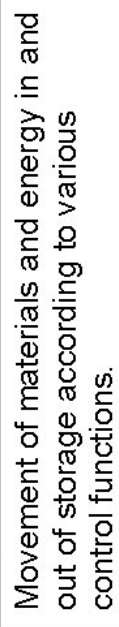 & 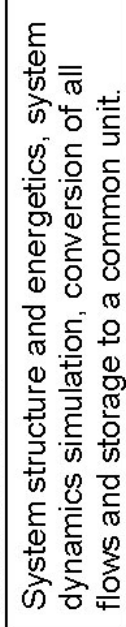 & 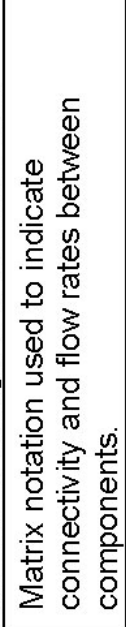 & \\
\hline & 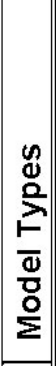 & $\begin{array}{l}\frac{00}{0} \\
\frac{10}{0} \\
\frac{0}{2} \\
\frac{0}{0} \\
3\end{array}$ & 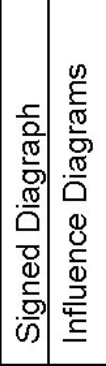 & 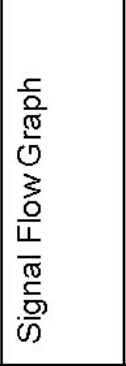 & 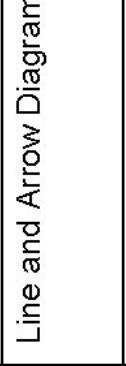 & 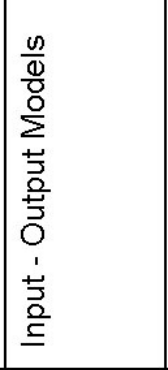 & 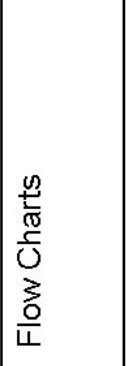 & 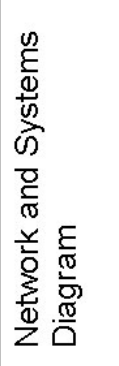 & 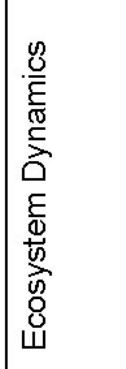 & 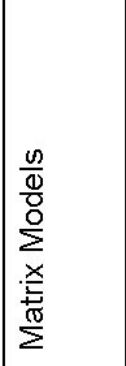 & \\
\hline & 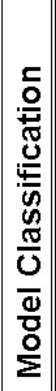 & $\begin{array}{l}\frac{00}{0} \\
\frac{10}{0} \\
\sum^{0} \\
0 \\
\frac{0}{0} \\
3\end{array}$ & 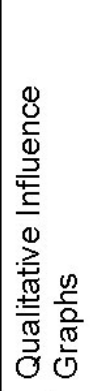 & 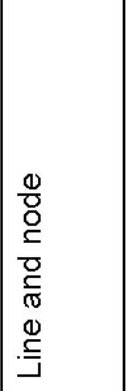 & 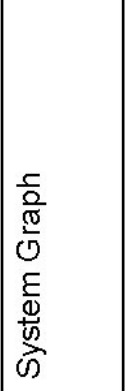 & 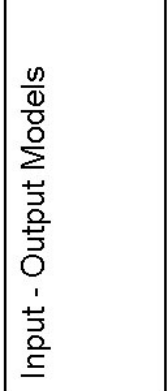 & 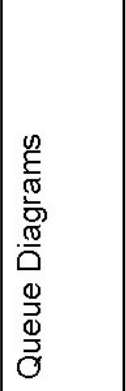 & 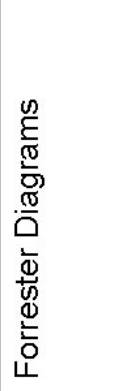 & 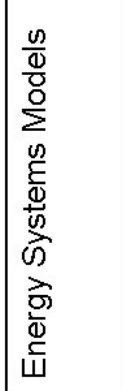 & 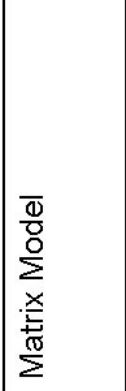 & \\
\hline
\end{tabular}




\section{APPENDIX B: GLOSSARY 1}

Adaptive management - An approach to natural resource management that incorporates monitoring of project outcomes and uses the monitoring results to make revisions and refinements to ongoing management actions (adapted from National Academy of Science (2002)).

Assessment endpoints - The actual environmental component that is the structure or function of interest or significance. Two things are defined - the specific endpoint valued, e.g., species, and the characteristic about the entity of concern that is important and at risk, e.g., nesting and feeding conditions (U.S. Environmental Protection Agency (USEPA) Risk Assessment Framework (1998)).

Benefits - Outcomes of management actions described in terms of relative value (adapted from O'Neil and Bartoldus (2002)).

Component - A discernable or distinct part that exists in the ecosystem, and together with other components, constitutes or encompasses the entirety of the ecosystem. Components may be organisms, physical structures, patterns, or processes.

Driver - Human activities or natural forces that cause changes in the system, resulting in environmental stress on ecosystem components (adapted from USAERDC and Harwell Gentile and Assoc. (2001)).

Endpoints - The selected components of an ecosystem that are ecologically significant or important, reflect public values, and are used to evaluate changes in the ecosystem. Endpoints can be quantified using standard units of measurement (performance criteria, metrics).

Essential ecosystem characteristics - The categories of properties or attributes that describe the major ecological components in any type of ecosystem (e.g., habitat quality, biological integrity, ecological processes, water quality, and hydrology) (Harwell et al. 1999).

Functions (processes) - The biological, physical, and chemical flows and transformations of energy and materials that occur in natural systems (O'Neil and Bartoldus 2002).

Goals - Articulation of societal values and desired ecosystem conditions. Goals are generally broad in nature (Harwell et al. 1999). Goals are further defined by objectives and endpoints. Goals are attained by implementation of management actions through attainment of objectives.

Objectives - Clear statements about desired future conditions of an ecosystem, for use in management and restoration. Objectives further define goals, using descriptions of target conditions for ecosystem components.

Pattern (structure) - A characteristic, repeating, or predictable occurrence of ecosystem components.

\footnotetext{
${ }^{1}$ Terms defined in part for use in Lubinski and Barko (2003).
} 
Performance criteria - Criteria for the status of endpoints (e.g., acceptable range, thresholds, or limits; based on scientific understanding of desired ecological conditions) (adapted from Harwell et al. (1999)).

Significant - Likely to have a material bearing on the decision-making process. Significance is based on institutional, technical, and public recognition. Resources and effects of alternative management actions are evaluated for significance (U.S. Water Resources Council 1983).

Stressor - A physical, chemical, or biological change that can affect an ecosystem or ecosystem component (USAERDC and Harwell Gentile and Assoc. 2001).

Structure - The spatial and temporal occurrence and arrangement of components in an ecosystem; the physical manifestation of patterns and processes (adapted from O'Neil and Bartoldus 2002).

\section{Glossary References:}

Harwell, M. A., Myers, V., Young, T., Bartuska, A., Gassman, N., Gentile, J. H., Harwell, C. C., Appelbaum, S., Barko, J., Causey, B., Johnson, C., McLean, A., Smola, R., Templet, P., and Tosini, S. (1999). "A framework for an ecosystem integrity report card," Bioscience 49(7), 543-556.

Lubinski, K. S., and Barko, J. W. (2003). "Mississippi River-Illinois Waterway System navigation feasibility study: Environmental science panel report,” ENV Report 52, U.S. Army Engineer Districts, Rock Island, St. Louis, and St. Paul. http://www2.mvr.usace.army.mil/umr-iwwsns/documents/ENV\%20Report\%2052.pdf

National Academy of Science. (2002). The Missouri River Ecosystem: Exploring the Prospects for Recovery, Washington, DC.

O'Neil, L .J., and Bartoldous. (2002). Selected definitions for ecological evaluation. Glossary for Corps training courses, Vicksburg, MS.

U.S. Army Engineer Research and Development Center and Harwell Gentile and Associates. (2001). "Conceptual models for coastal Long Island ecosystems: Fire Island to Montauk Point reformulation study," Draft report prepared for U.S. Army Engineer District, New York, Vicksburg, MS.

U.S. Environmental Protection Agency (USEPA). (1998). "Risk assessment framework."

U.S. Water Resources Council. (1983). Economic and environmental principles and guidelines for water and related land resources implementation studies. Washington, DC. 